\title{
Noradrenergic Modulation of Electrical Coupling in GABAergic Networks of the Hippocampus
}

\author{
Veronika Zsiros and Gianmaria Maccaferri \\ Department of Physiology, Feinberg School of Medicine, Northwestern University, Chicago, Illinois 60611
}

Noradrenergic modulation of cortical circuits is involved in information processing, regulation of higher functions, and prevention of epileptic activity. Here, we studied the effects of noradrenaline on the functional connectivity of GABAergic networks of the hippocampus and show that electrical synapses between interneurons are a novel target of noradrenergic modulation in vitro. Application of noradrenaline or of the selective $\beta$-adrenergic agonist isoproterenol decreased gap junction-based coupling in paired recordings from stratum lacunosum-moleculare interneurons by $\sim 40 \%$. Similar results were obtained after pharmacological stimulation of the adenylyl cyclase with forskolin. In contrast, the adenylyl cyclase antagonist MDL12330A [ $c i s-\mathrm{N}$-(2-phenylcyclopentyl)azacyclotridec-1-en-2-amine] or the specific protein kinase A (PKA) inhibitor H89 ( $N$-[2-( $p$-bromocinnamyl-amino)ethyl]-5-isoquinolinesulfonamide dihydrochloride) enhanced the basal strength of coupling by $\sim 30 \%$. In addition, PKA-mediated phosphorylation was critical for both isoproterenol- and forskolin-dependent regulation of coupling, because inclusion of the PKA antagonist KT5720 [(9S,10R,12R)-2,3,9,10,11,12-hexahydro10-hydroxy-9-methyl-1-oxo-9,12-epoxy-1H-diindolo[1,2,3-fg:3',2',1'-kl]pyrrolo[3,4-i][1,6]benzodiazocine-10-carboxylicacid hexyl ester] in the recording pipettes prevented modulation.

Lastly, we studied the effects of $\beta$-adrenergic modulation on mixed polysynaptic transmission within the GABAergic network. Isoproterenol depressed propagation of $\mathrm{GABA}_{\mathrm{A}}$ receptor-mediated synaptic currents, but did not change significantly direct GABAergic input, indicating that regulation of electrical coupling adds flexibility to the information flow generated by chemical synapses.

In conclusion, activation of $\beta$-adrenergic receptors in stratum lacunosum-moleculare GABAergic networks reduces electrical synaptic transmission via a cAMP/PKA signaling cascade, and affects the degree of synaptic divergence within the circuit. We propose that this dynamic modulation and interplay between electrical and chemical synaptic transmission in GABAergic networks contributes to the tuning of memory processes in vivo, and prevents hypersynchronous activity.

Key words: noradrenaline; GABAergic neuron; gap junction; cAMP; adenylate cyclase; network

\section{Introduction}

The hippocampus is a region of the brain involved in learning and memory (Squire et al., 2004) and has a low threshold for epilepsy. Monoaminergic projections originating from subcortical nuclei play an important role in shaping the ensemble dynamic activity required for these higher functions and contribute to the prevention of epileptiform discharges. In particular, noradrenergic control of the hippocampus has been implicated in memory consolidation and retrieval (Gibbs and Summers, 2002; Murchinson et al., 2004), novelty detection (Sara et al., 1995; Lisman and Otmakhova, 2001), and control of hyperexcitability (Chauvel and Trottier, 1986). At the cellular level, modulation of both pyramidal cells and GABAergic interneurons (Nicoll et al., 1990; Bergles et al., 1996; Parra et al., 1998) via specific noradrenergic receptors has been reported.

\footnotetext{
Received 0ct. 10, 2007; revised Jan. 7, 2008; accepted Jan. 8, 2008.

This work was supported by National Institute of Mental Health Grant MH067561 (G.M.). We thank Drs. S. DeVries, G. Shepherd, Jr., and N. Spruston for comments on a previous version of this manuscript.

Correspondence should be addressed to Gianmaria Maccaferri, Department of Physiology, Northwestern University Medical School, 303 East Chicago Avenue, Tarry Building, Room 5-707 M211, Chicago, IL 60611. E-mail: g-maccaferri@northwestern.edu.

DOI:10.1523/JNEUROSCI.4616-07.2008

Copyright $\odot 2008$ Society for Neuroscience $\quad$ 0270-6474/08/281804-12\$15.00/0
}

In the CA1 area, noradrenaline (NA) is released by fibers originating from the locus ceruleus (Loy et al., 1980). Most commonly, varicosities lack postsynaptic specializations and are thought to act functionally by volume transmission (Agnati et al., 1995). However, when synapses are established, GABAergic interneurons are often the preferential postsynaptic targets (Milner and Bacon, 1989). Although both $\alpha 1$ noradrenergic receptormediated suppression of a potassium conductance (Bergles et al., 1996) and $\beta$ noradrenergic receptor-dependent increase of the hyperpolarization-activated current (Maccaferri and McBain, 1996) have been observed in a variety of interneurons, the complete actions of noradrenaline on hippocampal GABAergic networks are not fully understood. For example, at present, nothing is known about the functional impact of NA on the synaptic connectivity of GABAergic networks.

A dense plexus of noradrenergic fibers runs through stratum lacunosum-moleculare (Oleskevich et al., 1989) and colocalizes with a network of local interneurons connected via gap junctions (Price et al., 2005; Zsiros and Maccaferri, 2005; Zsiros et al., 2007), thus suggesting the possibility of noradrenergic control of electrical coupling. Electrical coupling in stratum lacunosummoleculare interneurons has been shown to occur frequently [values ranging between 33 and $83 \%$ of tested pairs were reported 
coupled (Price et al., 2005; Zsiros and Maccaferri, 2005)], to be important for oscillatory and firing synchronization (Price et al., 2005), and to enhance network synaptic divergence by propagating mixed polysynaptic events (Zsiros et al., 2007). Therefore, modulation of coupling could endow a local source of GABA release with additional flexibility in the spatiotemporal domain.

Here, we have taken advantage of direct paired recordings from connected interneuron pairs to test the hypothesis that NA modulates electrical coupling of hippocampal stratum lacunosum-moleculare GABAergic networks. Our results indicate that NA reduces electrical coupling predominantly via $\beta$-adrenergic receptors ( $\beta$-ARs) via a cAMP/protein kinase $\mathrm{A}$ (PKA)-dependent pathway. Furthermore, this regulation affects the network by reducing the propagation of postsynaptic currents and hence functionally decreases synaptic divergence. We propose that this previously undescribed modulation plays a role in the control of the hippocampus in vivo and can affect higher cognitive functions.

\section{Materials and Methods}

\section{Slice preparation}

Slices were prepared from young Sprague Dawley rats [postnatal day 12 (P12) to P23]. Rats were deeply anesthetized using isoflurane in compliance with the guidelines provided by the Institutional Animal Care and Use Committee of Northwestern University and the National Institutes of Health. After deep anesthesia, rats were quickly decapitated, and the brain was removed from the skull in a small container filled with chilled "cutting" solution of the following composition (in mM): 234 sucrose, 28 $\mathrm{NaHCO}_{3}, 2.5 \mathrm{KCl}, 1.25 \mathrm{NaH}_{2} \mathrm{PO}_{4}, 0.5 \mathrm{CaCl}_{2}, 7 \mathrm{MgSO}_{4}, 7$ glucose, 1 ascorbic acid, 3 pyruvic acid saturated with $95 \% \mathrm{O}_{2}$ and $5 \% \mathrm{CO}_{2}$ at $\mathrm{pH}$ 7.4. A vibrating microtome (VT1000S; Leica, Nussloch, Germany) was used to cut sections of $350 \mu \mathrm{m}$ in chilled cutting solution. Slices were then stored in an incubation chamber at $34-35^{\circ} \mathrm{C}$ for at least $30 \mathrm{~min}$, and then stored at room temperature until use. The "storing" solution was of the following composition (in mM): $130 \mathrm{NaCl}, 24 \mathrm{NaHCO}_{3}, 3.5 \mathrm{KCl}, 1.25$ $\mathrm{NaH}_{2} \mathrm{PO}_{4}, 2 \mathrm{CaCl}_{2}, 1 \mathrm{MgSO}_{4}$, and 10 glucose saturated with $95 \% \mathrm{O}_{2}$ and $5 \% \mathrm{CO}_{2}$ at $\mathrm{pH} 7.4$.

\section{Whole-cell recordings}

Conventional patch-clamp recordings were performed. Slices were superfused with preheated "recording" solution maintained at a constant temperature $\left(32-35^{\circ} \mathrm{C}\right)$. Recording solution was identical with the storing solution with the addition of the following drugs to block excitatory and inhibitory synaptic transmission: $12.5 \mu \mathrm{M}$ gabazine (SR-95531), 20 $\mu \mathrm{M}$ 6-nitro-7-sulfamoylbenzo $(f)$ quinoxaline-2,3-dione (NBQX), $50 \mu \mathrm{M}$ D-AP5, $2 \mu \mathrm{M}$ (2S)-3-[[(1S)-1-(3,4-dichlorophenyl)ethyl] amino-2hydroxypropyl] (phenylmethyl)phosphinic acid (CGP55845), except for the experiments shown in Figure 9, in which gabazine was omitted.

Cells were observed and selected for recording by means of $40 \times$ infrared (IR) immersion differential interference contrast (DIC) objective applied to a direct microscope (Olympus, Tokyo, Japan) equipped with an infrared camera system (DAGE-MTI, Michigan City, IN). Interneurons were chosen in the CA1 stratum lacunosum-moleculare, preferably close to the hippocampal fissure, as in Zsiros and Maccaferri (2005). Pipettes were pulled from borosilicate thin glass capillaries and filled with the appropriate filtered intracellular solution to a 1.5-5 $\mathrm{M} \Omega$ final resistance, as detailed below. Recordings were performed using a Multiclamp 700 amplifier (Molecular Devices, Sunnyvale, CA). Data were filtered at $3 \mathrm{kHz}$ and digitized at $10-20 \mathrm{kHz}$ using a Digidata A/D board and the Clampex 9 program suite (Molecular Devices). Series resistances were constantly monitored by injecting a $5 / 10 \mathrm{mV}$ step in voltage-clamp or a $-100 \mathrm{pA}$ pulse in current-clamp configuration. Series resistances were not compensated in voltage-clamp configuration, whereas they were balanced via a bridge circuit in current-clamp mode.

\section{Intracellular solutions}

We used three different types of intracellular solutions, as follows.

K-methylsulfate-based solution for current-clamp recordings.
K-methylsulfate-based solution for current-clamp recordings contained the following (in mM): $125 \mathrm{~K}$-methylsulfate, $4 \mathrm{ATP}-\mathrm{Mg}_{2}, 4 \mathrm{NaCl}, 0.3$ GTP, $16 \mathrm{KHCO}_{3}$ equilibrated with $95 \% \mathrm{O}_{2}$ and $5 \% \mathrm{CO}_{2}$ to $\mathrm{pH} 7.3$. In the experiments shown in Figure $6 A,(9 S, 10 R, 12 R)-2,3,9,10,11,12$ hexahydro-10-hydroxy-9-methyl-1-oxo-9,12-epoxy- $1 \mathrm{H}$-diindolo[1,2,3-fg: $3^{\prime}, 2^{\prime}, 1^{\prime}$-kl] pyrrolo[3,4-i] [1,6] benzodiazocine-10-carboxylicacid hexyl ester (KT5720) $(1 \mu \mathrm{M})$ was also included.

Cs-methylsulfate, lidocaine $\mathrm{N}$-ethyl chloride-based solution for currentclamp recordings. Cs-methylsulfate, lidocaine $N$-ethyl chloride (QX-314)based solution for current-clamp recordings contained the following (in mM): 125 Cs-methylsulfate, 4 ATP- $\mathrm{Mg}_{2}, 4 \mathrm{NaCl}, 0.3 \mathrm{GTP}, 16 \mathrm{KHCO}_{3}, 10$ $\mathrm{N}$-2(2,6-dimethylphenylcarbamoylmethyl)triethylammonium chloride (QX-314-Cl) equilibrated with $95 \% \mathrm{O}_{2}$ and $5 \% \mathrm{CO}_{2}$ to $\mathrm{pH} 7.3$. QX-314 was included in the intracellular solution at high concentration to block voltagedependent conductances and $\mathrm{GABA}_{\mathrm{B}}$ receptor-operated potassium currents. KT5720 was also included in the experiments shown in Figure $7 B$. When this intracellular solution was used, external 4-ethylphenylamino-1,2dimethyl-6-methylaminopyrimidinium chloride (ZD7288) (100 $\mu \mathrm{M})$ was constantly present in the bath to avoid time-dependent effects on membrane input resistance caused by the intracellular blockade of the hyperpolarization-activated current by QX-314 and to provide additional block of intrinsic conductances $\left[I_{\mathrm{h}}\right.$ (Maccaferri and McBain, 1996); potassium channels (Do and Bean, 2003)].

Cs-chloride-based solution for voltage-clamp recordings. Cs-chloridebased solution for voltage-clamp recordings contained the following (in mM): $125 \mathrm{CsCl}, 4$ ATP- $\mathrm{Mg}_{2}, 10 \mathrm{NaCl}, 0.3 \mathrm{GTP}, 16 \mathrm{KHCO}_{3}, 5 \mathrm{QX}-314-\mathrm{Cl}$ equilibrated with $95 \% \mathrm{O}_{2}$ and $5 \% \mathrm{CO}_{2}$ to $\mathrm{pH}$ 7.3. As for the Csmethylsulfate, QX-314-based solution described above, external ZD7288 $(100 \mu \mathrm{M})$ was constantly present in the bath. Liquid junction potential was experimentally determined and subtracted off-line (Zsiros et al., 2007).

Experiments shown in Figures 1, 3, 4, 5B, and 6 were performed using the K-methylsulfate-based intracellular solution for current-clamp recordings. The experiments shown in Figures 2 and 7 were performed using the Cs-methylsulfate, QX-314 current-clamp intracellular solution. Experiments in Figure $5 A$ were obtaining by pooling together the results from both K-methylsulfate and Cs-methylsulfate, QX-314 current-clamp-based solutions. Finally, experiments of Figure 9 were performed with pipettes filled with Cs-chloride-based voltage-clamp solution. As shown in supplemental Figure 1 (available at www. jneurosci.org as supplemental material), modulation of coupling did not depend on the intracellular solution used.

\section{Evaluation of electrical coupling and junctional conductance in paired current-clamp experiments}

We tested for the presence of gap junctions between pairs by repetitively injecting a $500 \mathrm{~ms}$ current step of $-100 \mathrm{pA}$. Cells were considered coupled if they had a DC coefficient coupling (cc) (ratio of the voltage deflection in the noninjected cell to the voltage deflection in the injected cell measured during the last $130 \mathrm{~ms}$ of the stimulus) value higher than 0.005 and the shape of the electrotonic response was recognizable in the recording from the noninjected cell. The effective junctional conductance $\left(G_{\mathrm{j}}\right)$ was calculated according to the following equation: $G_{\mathrm{j}}=$ $1 /\left[\left(R_{\mathrm{in} 2} / \mathrm{cc}\right)-R_{\mathrm{in} 2}\right]$, where $R_{\mathrm{in} 2}$ is the input resistance of the noninjected neuron and cc is the DC coefficient coupling. In addition, to assess the likelihood that intrinsic properties could interfere with the observed modulation of coupling, we compared results obtained with K-methylsulfate versus Cs-methylsulfate, QX-314-based solutions (supplemental Fig. 1, available at www.jneurosci.org as supplemental material). We reasoned that, if the modulation of intrinsic properties introduced a significant error in the estimation of $G_{j}$, different results should be observed using intracellular solution maintaining (K-methylsulfate based) or disrupting (Cs-methylsulfate, QX-314 based) intrinsic properties. As shown in supplemental Figure 1 (available at www.jneurosci.org as supplemental material), forskolin-induced modulation of $G_{\mathrm{j}}$ was observed independently of the intracellular solution used, suggesting that the involvement of an intrinsic conductance is unlikely. 
Drugs

The following drugs were from Tocris Cookson (Ellisville, MO): CGP55845, D-AP5, gabazine, isoproterenol, KT5720, NBQX, and ZD7288. 1,9-Dideoxy forskolin, forskolin, cis- $N$-(2-phenylcyclopentyl)azacyclotridec-1-en-2-amine (MDL12330A), and noradrenaline were from Sigma-Aldrich (St. Louis, MO). Lastly, $N$-[2-( $p$-bromocinnamylamino)ethyl]-5-isoquinolinesulfonamide dihydrochloride (H89) was from EMD Biosciences (La Jolla, CA).

\section{Analysis of spontaneous events in single-cell recordings}

Spontaneous currents recorded from single neurons in voltage clamp held at $-15 \mathrm{mV}$ were analyzed using the Clampfit 9.0 (Molecular Devices), Origin Pro 7.0 (Originlab, Northampton, MA), Prism 3.0 (GraphPad Software, San Diego, CA), and Microsoft Excel (Microsoft, Redmond, WA) suites of programs. Events were first collected using the template-based analysis feature of Clampfit, and then reviewed by visual inspection. As extensively discussed in a previous publication (Zsiros et al., 2007), voltage clamp in an interneuron may propagate across electrical synapses, and help discriminate between direct- versus gap junctionpropagated synaptic input. Although the propagation of voltage clamp may be strongly attenuated in the coupled cells, this attenuation may be much less at membrane domains close to the site of the electrical connection. Therefore, synaptic input impinging close to site of the gap junctions may be recorded (Zsiros et al., 2007). Coupled cells that are not subjected to the chloride loading of the recorded electrode have an estimated reversal potential for $\mathrm{GABA}_{\mathrm{A}}$ receptor-mediated events $\left(E_{\mathrm{GABA}-\mathrm{A}}\right)$ of approximately $-70 \mathrm{mV}$ (Zsiros et al., 2007). Hence, even with a severe degradation of voltage clamp, when the voltage command is set at -15 $\mathrm{mV}$, events generated in coupled cells at postsynaptic domains close to the site(s) of the gap junction(s) appear with an outward polarity. In contrast, at $-15 \mathrm{mV}$, direct GABAergic input on a cell recorded with our Cs-chloride-based intracellular solution (estimated $E_{\mathrm{GABA}-\mathrm{A}}$ is $\sim 0 \mathrm{mV}$ ) is recorded as inward deflections. Therefore, the opposite polarities can be used to reveal the site of origin of the synaptic inputs.

\section{Statistical methods}

Electrical coupling was evaluated bidirectionally for every pair studied by using a protocol similarly to the one shown in Figure $1 A$, with sequential injection of current steps in the two neurons, repeated every $2.5 \mathrm{~s}$. Negative current steps were used to obtain electrotonic responses and minimize the activation of voltage-dependent conductances. Traces shown in the insets of the illustrations are averages of 24 traces collected during a period of $1 \mathrm{~min}$.

We assumed that the modulation of cell -to-cell $_{2}$ coupling being measured was independent of the modulation of the cell ${ }_{2}$-to-cell ${ }_{1}$ coupling for the following reasons. First, noradrenergic modulation of intrinsic conductances in interneurons has been repeatedly shown (Bergles et al., 1996; Maccaferri and McBain, 1996, Parra et al., 1998, Banks et al., 2002). Therefore, we wanted to avoid the assumption that modulation of coupling indexes must reflect modulation of the junctional conductance across the pair. Although $\mathrm{cc}$ and $G_{\mathrm{j}}$ imply an electrical connection, their modulation does not necessary imply that the electrical connection is the target of the modulation. Modulation of coupling indexes could also be achieved simply by modulation of the membrane input resistance of the noninjected cell of the pair. It is important to underlie that the estimation of $G_{j}$ assumes a junctional conductance between two isopotential neurons, which is a condition that may not be always satisfied. Furthermore, heterologous coupling of neurogliaform cells (Simon et al., 2005; Zsiros and Maccaferri, 2005) has been reported and asymmetrical modulation of the intrinsic properties of the cells of the pair should not be necessarily ruled out. Therefore, although unlikely, changes in a voltage-dependent conductance insensitive to Cs, QX-314, and ZD7288 cannot be completely excluded a priori. Second, electrical synapses between cortical neurogliaform interneurons are often located asymmetrically in the cells of the pair [for example, soma-dendrite, proximal-distal dendrite ( $\mathrm{Si}$ mon et al., 2005)]. Thus, propagation of pulses injected at the somas of the two cells of the pair reflects a bidirectional nonlinear process that needs to be evaluated as an independent measurement, and cannot be subjected to a linear operation such as averaging. Third, treating every connection separately increases the power of the pairing/matching pro- cedure of the statistical tests used (see below) and provides an internal control that both connections are modulated in the same direction. Fourth and last, an independent evaluation avoids the systematic bias that would be introduced by averaging the bidirectional $c c$ and $G_{j}$ within pairs. Because of the large spread of the distribution of the ratio of the bidirectional coupling coefficients [Zsiros and Maccaferri (2005), their Fig. 3], averaging would predominantly reflect modulation in the direction with the largest coupling coefficient, and thus a systematic bias would be introduced.

Statistical analysis was performed using the Origin and Prism software packages. Coupling coefficients do not follow a normal distribution (Zsiros and Maccaferri, 2005); therefore, we used nonparametric tests when comparing their absolute values. We also made no assumptions on the distribution of the absolute values of junctional conductances. Nonparametric tests used were as follows: (1) Wilcoxon's signed rank test (abbreviated as W) and (2) Friedman's test with Dunn's multiple comparison post test (abbreviated as F/D). Both tests pair/match the observation for individual connections in control versus the various experimental treatments. The junctional conductance and coupling coefficient absolute values refer to an averaged period of $5 \mathrm{~min}$ in control or drugexposed conditions. In the case of supplemental Figure 1 (available at www.jneurosci.org as supplemental material), we verified that the distribution of the normalized effect of forskolin was Gaussian [KolmogorovSmirnov test, with the Dallal and Wilkinson (1986) approximation to Lilliefors' method to calculate $p$ ] and hence used a parametric two-way ANOVA. The level of significance chosen for all statistical tests was 0.05 . Data are shown as mean \pm SEM. Linear regression shown in Figure 8 was weighted according to the SEM of the datapoints.

\section{Results \\ Modulation of electrical coupling between GABAergic interneurons by noradrenaline and specific noradrenergic agonists}

We performed simultaneous whole-cell recordings from pairs of electrically coupled interneurons in CA1 stratum lacunosummoleculare (Fig. 1). As shown in Figure 2, after blockade of ionotropic GABAergic and glutamatergic synaptic transmission, application of NA $(20 \mu \mathrm{M})$ to the external medium reduced both the bidirectional DC coupling coefficient (cc, $0.083 \pm 0.016$ in control vs $0.052 \pm 0.011$ in the presence of NA; $p<0.05 ; n=14$ bidirectional connections from seven pairs; $\mathrm{W}$ test) and estimated junctional conductance between the two neurons $\left(G_{j}\right.$, $0.565 \pm 0.158 \mathrm{nS}$ in control vs $0.405 \pm 0.129 \mathrm{nS}$ after the addition of NA; $p<0.05 ; n=14$ bidirectional connections from seven pairs; $\mathrm{W}$ test) (for details on the estimation of the junctional conductance, see Materials and Methods). The effect of NA was closely mimicked by the selective $\beta$-AR agonist isoproterenol ( 10 $\mu \mathrm{M}$ ), which reduced the $\mathrm{cc}$ from $0.107 \pm 0.040$ in control conditions to $0.079 \pm 0.032$ in the presence of the drug ( $n=10$ bidirectional connections from five pairs; $p<0.05$; W test) and the estimated junctional conductance from $0.726 \pm 0.312$ to $0.489 \pm$ $0.208 \mathrm{nS}$ ( $n=10$ bidirectional connections from five pairs; $p<$ 0.05 ; $\mathrm{W}$ test). In summary, these initial experiments indicated that electrical coupling between stratum lacunosum-moleculare interneurons can be depressed by noradrenaline and by the pharmacological activation of $\beta$-ARs.

\section{Intracellular cAMP levels are a critical determinant of bidirectional coupling strength in stratum lacunosum- moleculare GABAergic networks}

Although $\beta$-ARs can use several signaling pathways, the most common result of their activation is an elevation in the intracellular levels of cAMP (Raymond, 1995). Therefore, we performed additional experiments to clarify whether a cAMP-mediated pathway was involved in the observed modulation. We raised 
A

B
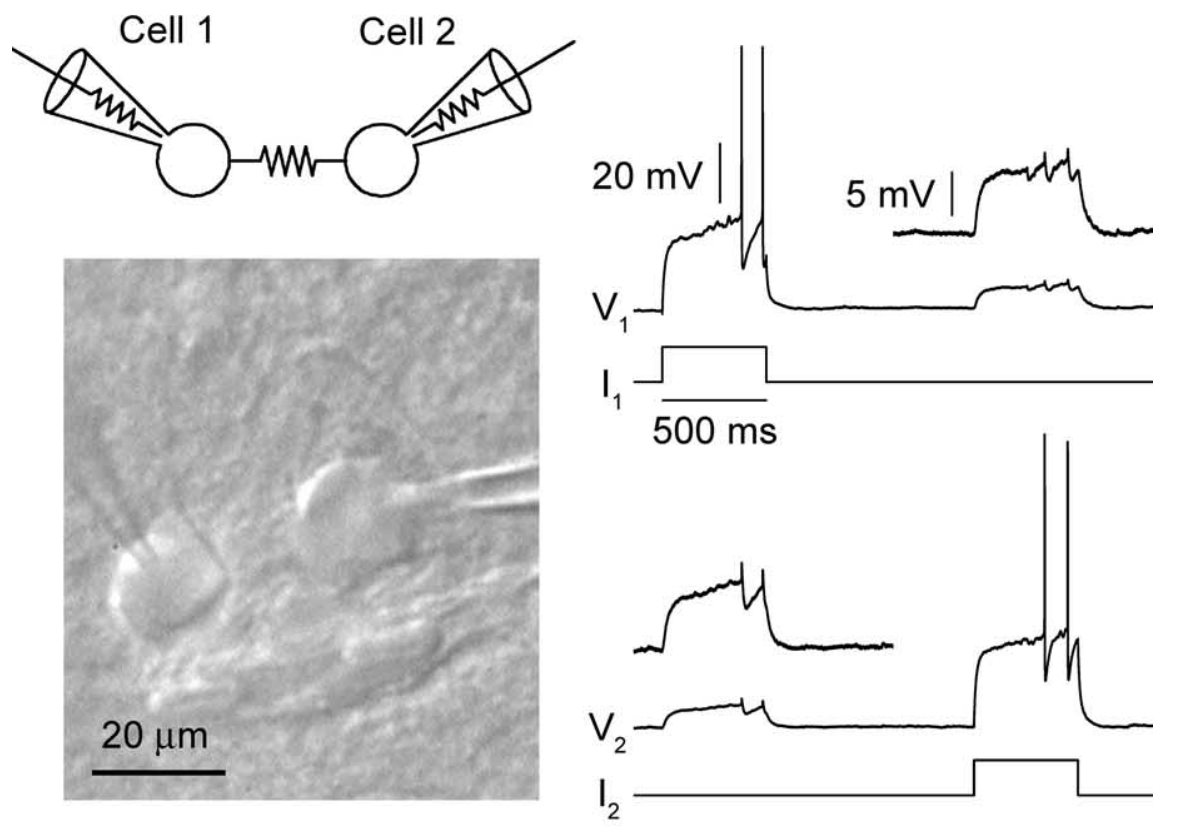

C
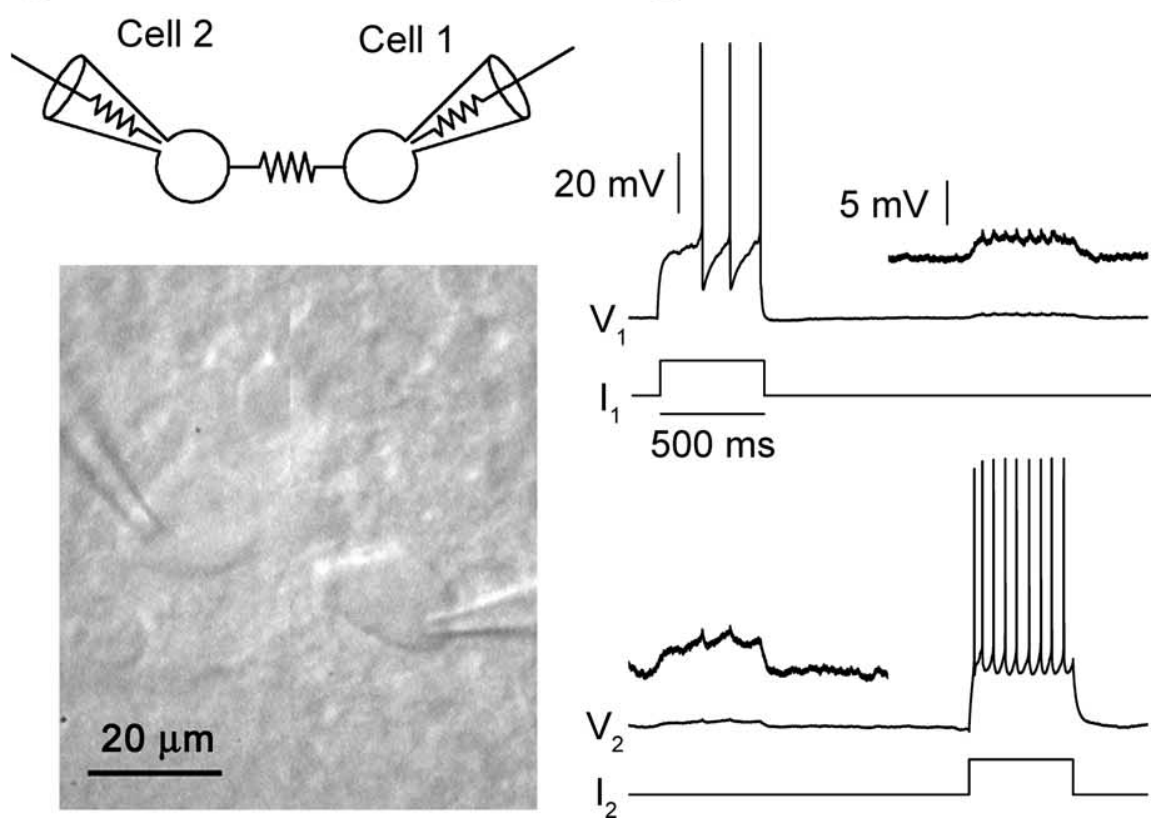

Figure 1. Direct demonstration of electrical coupling between two late-spiking interneurons by paired recording. $\boldsymbol{A}$, Cartoon of the experimental configuration (top) and IR-DIC image of the pair in the living slice (bottom). $\boldsymbol{B}$, Sequential injection of a depolarizing current step $(150 \mathrm{pA})$ in cell ${ }_{1}$ and cell ${ }_{2}$ generates an attenuated response in the noninjected neuron. Insets show the attenuated responses at enhanced magnification; notice the presence of spikelets. $V_{1}$ and $V_{2}$ indicate the membrane potential recorded from cell $I_{1}$ and cell $l_{2}$, respectively, and $I_{1}$ and $I_{2}$ the current injected through the electrode. $\boldsymbol{C}$ and $\boldsymbol{D}$ illustrate the same experiment in a pair of interneurons with different firing patterns. Step injected, $100 \mathrm{pA}$.
$\mathrm{nS}$ in the presence of the drug; $n=20 \mathrm{bi}$ directional connections from 10 pairs; $p<$ 0.05 ; $\mathrm{W}$ test). The result appeared to be specific to forskolin-induced stimulation of adenylyl cyclase, because application of the inactive analog dideoxyforskolin (50 $\mu \mathrm{M})$ did not change significantly either coupling coefficient or estimated junctional conductance values (cc was $0.079 \pm$ 0.012 in control vs $0.071 \pm 0.010$ in the presence of dideoxyforskolin; $n=20$ bidirectional connections from 10 pairs; $p>$ 0.05 ; W test; whereas $G_{j}$ was $0.700 \pm 0.108$ $\mathrm{nS}$ in the absence vs $0.733 \pm 0.101 \mathrm{nS}$ in the presence of the drug; $n=20$ bidirectional connections from 10 pairs; $p>$ 0.05). Thus, raising intracellular cAMP levels appeared to depress coupling, consistent with our hypothesized role of $\beta$-ARs. In contrast, if basal levels of cAMP had a tonic effect on coupling, then inhibition of adenylyl cyclase activity with the irreversible adenylyl cyclase antagonist MDL12330A (Lippe and Ardizzone, 1991) would be expected to potentiate coupling. In four of six connected pairs tested (Fig. 4 ), application of MDL12330A (10 $\mu \mathrm{M})$ increased both coupling coefficient and estimated junctional conductance (cc was $0.107 \pm 0.013$ in control vs $0.144 \pm 0.023$ in the presence of MDL12330A; $n=8$ bidirectional connections from four pairs; $p<0.05 ; \mathrm{F} / \mathrm{D}$ test; whereas $G_{\mathrm{j}}$ was $1.026 \pm$ $0.112 \mathrm{nS}$ in the absence vs $1.362 \pm 0.146 \mathrm{nS}$ in the presence of the drug; $n=8$ bidirectional connections from four pairs; $p<$ 0.05; F/D test). As an additional control that adenylyl cyclase was effectively blocked by the drug, we verified that forskolin $(50 \mu \mathrm{M})$ had no effects in the presence of MDL12330A. The addition of forskolin did not change either the coupling coefficient or the estimated junctional conductance (cc was $0.144 \pm 0.023$ in MDL12330A vs $0.133 \pm 0.018$ in the presence of both MDL12330A and forskolin; $n=8$ bidirectional connections from four pairs; $p>0.05$; F/D test; similarly, $G_{j}$ was $1.362 \pm 0.146 \mathrm{nS}$ before vs $1.315 \pm 0.109$ $\mathrm{nS}$ after forskolin addition; $n=8$ bidirectional connections from four pairs; $p>$ 0.05 ). Thus, the dynamic levels of intracellular cAMP appear to bidirectionally regulate electrical coupling in stratum lacunosum-moleculare interneurons. intracellular cAMP levels pharmacologically by direct activation of the adenylyl cyclase. As shown in Figure 3, superfusion of the slice with forskolin $(50 \mu \mathrm{M})$ reduced both the coupling coefficient and estimated junctional conductance (cc was $0.080 \pm 0.009$ in control vs $0.052 \pm 0.008$ in the presence of forskolin; $n=20$ bidirectional connections from 10 pairs; $p<0.05$; W test; whereas $G_{\mathrm{j}}$ was $0.780 \pm 0.105 \mathrm{nS}$ in the absence vs $0.550 \pm 0.105$

\section{The effects of cAMP on coupling strength are mediated by PKA}

We reasoned that if cAMP was a second messenger involved in the regulation of electrical coupling, then it was likely to act via PKA-mediated phosphorylation. We addressed this issue by taking advantage of two different PKA inhibitors such as H89 (Fig. 5) (bath applied; 8-20 $\mu \mathrm{M}$ ) and KT5720 (Fig. 6) (intracellularly loaded via the recording pipette; $1 \mu \mathrm{M}$ ). 
A
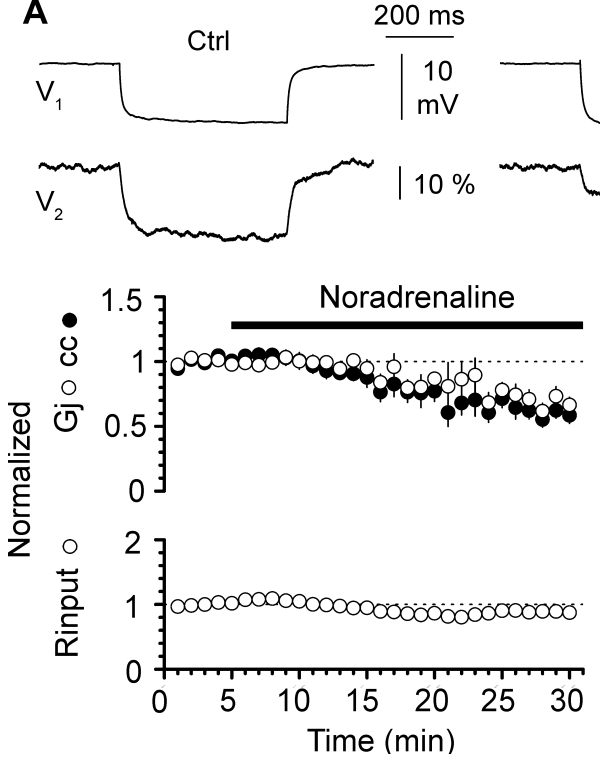

NA
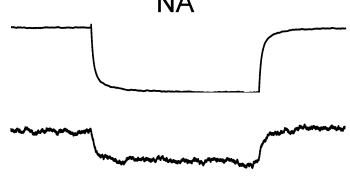

$\mathrm{Gj}(\mathrm{nS})$
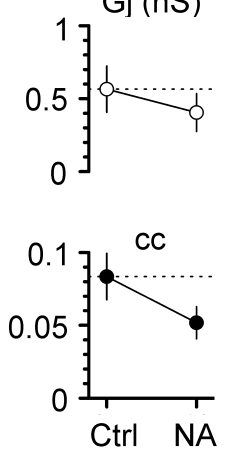

B
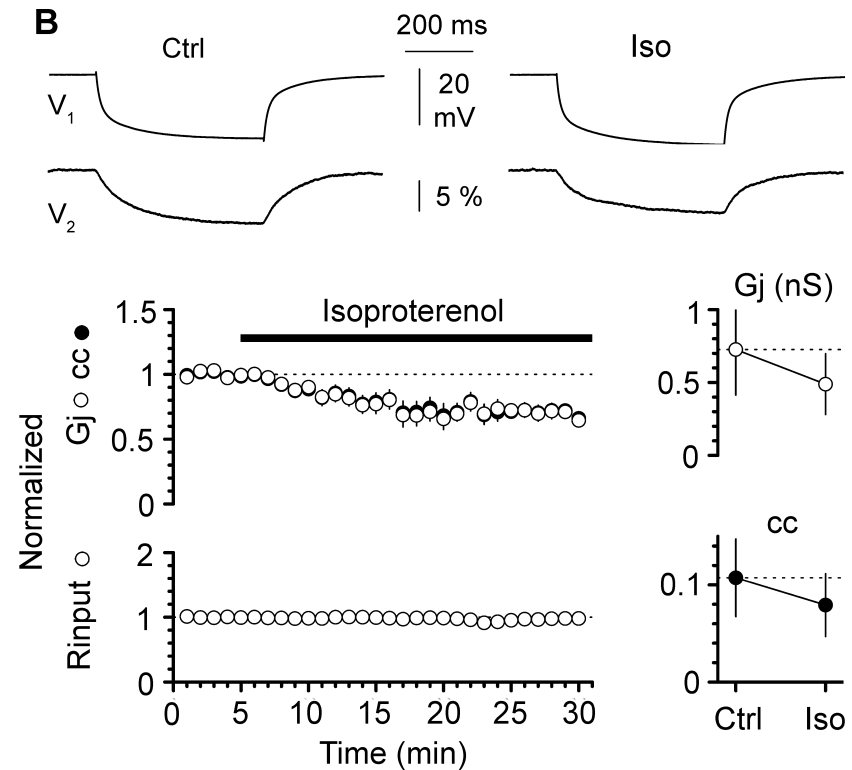
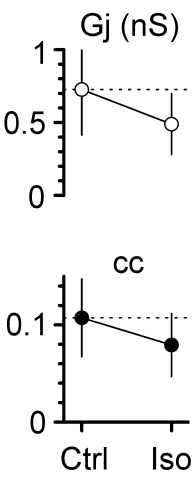

Figure 2. Electrical coupling between stratum lacunosum-moleculare interneurons is modulated by $\beta$-adrenergic receptors. $\boldsymbol{A}$, Application of noradrenaline ( $20 \mu \mathrm{m}$ ) reduces the estimated $G_{\mathrm{j}}$ ( for details, see Materials and Methods) and the cc. The time course of the effect of noradrenaline on the normalized cc, $G_{\mathrm{j}}\left(n=14\right.$ bidirectional connections), and $R_{\text {input }}(n=14$ neurons; absolute values were $213 \pm 24 \mathrm{M} \Omega$ in control vs $188 \pm 24 \mathrm{M} \Omega$ in the presence of noradrenaline) are shown in the left plots, whereas the change in absolute values of $G_{\mathrm{j}}$ and $c c$ ( $n=14$ bidirectional connections) are shown in the right summary graphs (Ctrl, control). Error bars are SEM. The top insets show averaged traces recorded from the cells of a pair showing the decreased propagation of an electrotonic response. The voltage response in the current injected cell $\left(V_{1}\right)$ is shown in millivolts, whereas the propagated response in the noninjected neurons $\left(V_{2}\right)$ is displayed as percentage of the steady-state value of $V_{1}$. B , Panels are organized as in $\boldsymbol{A}$, but the effect of selective $\beta$-adrenergic receptor agonist isoproterenol (Iso) (10 $\mu \mathrm{m}$ ) is shown. Notice the large reduction of coupling and estimated junctional conductance after application of the $\operatorname{drug}\left(n=10\right.$ bidirectional connections; $R_{\text {input }}$ was $209 \pm 16 \mathrm{M} \Omega$ in control vs $205 \pm 18 \mathrm{M} \Omega$ in the presence of isoproterenol; $n=10$ neurons).

A

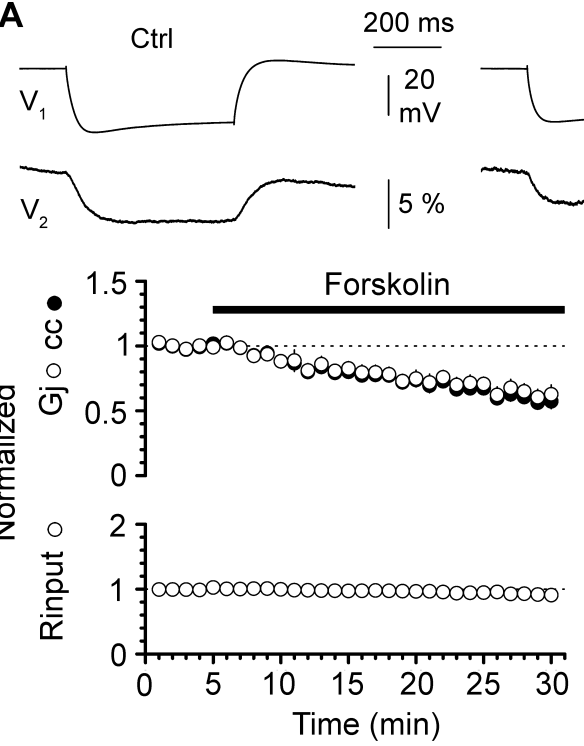

Frsk

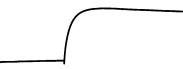

$\mathrm{Gj}(\mathrm{nS})$
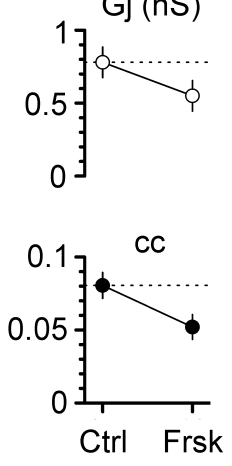

B

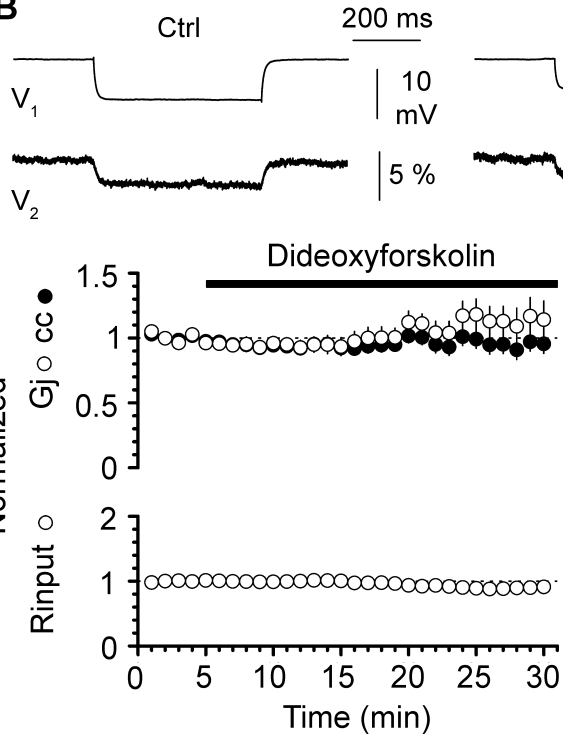

Dfrsk

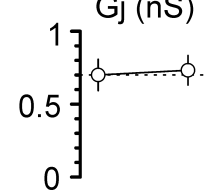

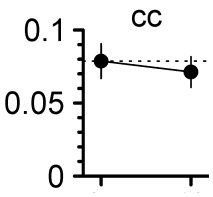

Ctrl Dfrsk

Figure 3. Pharmacological elevation of intracellular cAMP levels reduces coupling between interneurons. $A$, Bath application of the adenylyl cyclase stimulator forskolin (50 $\mu \mathrm{m}$ ) reduces the estimated $G_{\mathrm{j}}$ and the $c c$. Summary plots of the normalized $G_{\mathrm{j}}, c \mathrm{c}\left(n=20\right.$ bidirectional connections), and $R_{\text {input }}(n=20$ neurons; absolute values were $139 \pm 16 \mathrm{M} \Omega$ in control and $129 \pm 15 \mathrm{M} \Omega$ in the presence of the drug) are shown in the left side of the figure, whereas plots of the actual values of $G_{\mathrm{j}}$ and $c c$ ( $n=20$ bidirectional connections) are shown in the right (Ctrl, control; Frsk, forskolin). Error bars are SEM. Averaged traces from a coupled pair are shown in the top inset. Electrotonic responses to current injection recorded in the first cell of the pair $\left(V_{1}\right)$ are shown in millivolts, whereas propagated responses to the noninjected cell $\left(V_{2}\right)$ are expressed as percentage of the steady state of $V_{1}$. $\boldsymbol{B}$, Similar experiment using the inactive analog dideoxyforskolin ( $50 \mu \mathrm{m}$ ) shows no effects on coupling. The organization of the plots and traces is identical with that of $\boldsymbol{A}$ (Dfrsk, dideoxyforskolin). Data from $n=20$ connections and 20 neurons. Average $R_{\text {input }}$ was $129 \pm 11$ M $\Omega$ in control versus $111 \pm 9 \mathrm{M} \Omega$ after application of dideoxyforskolin.

Bath application of $\mathrm{H} 89$ induced a potentiation of electrical coupling. Both coefficient coupling and estimated junctional conductance increased from respective values of $0.071 \pm 0.014$ and $0.465 \pm 0.079 \mathrm{nS}$ in control to $0.084 \pm 0.016$ and $0.602 \pm$ $0.094 \mathrm{nS}$ in the presence of the inhibitor $(n=14$ bidirectional connections from seven pairs; $p<0.05$; $\mathrm{W}$ test). H89 was also effective in preventing forskolin-induced modulation of coupling. No significant changes were observed either in coupling coefficient or estimated junctional conductance when forskolin was added to H89 in the bath (cc was $0.074 \pm 0.012$ in H89 vs $0.068 \pm 0.013$ after the addition of forskolin; $n=8$ bidirectional connections from four pairs; $p>0.05 ; \mathrm{W}$ test; and $G_{\mathrm{j}}$ was $0.801 \pm$ 

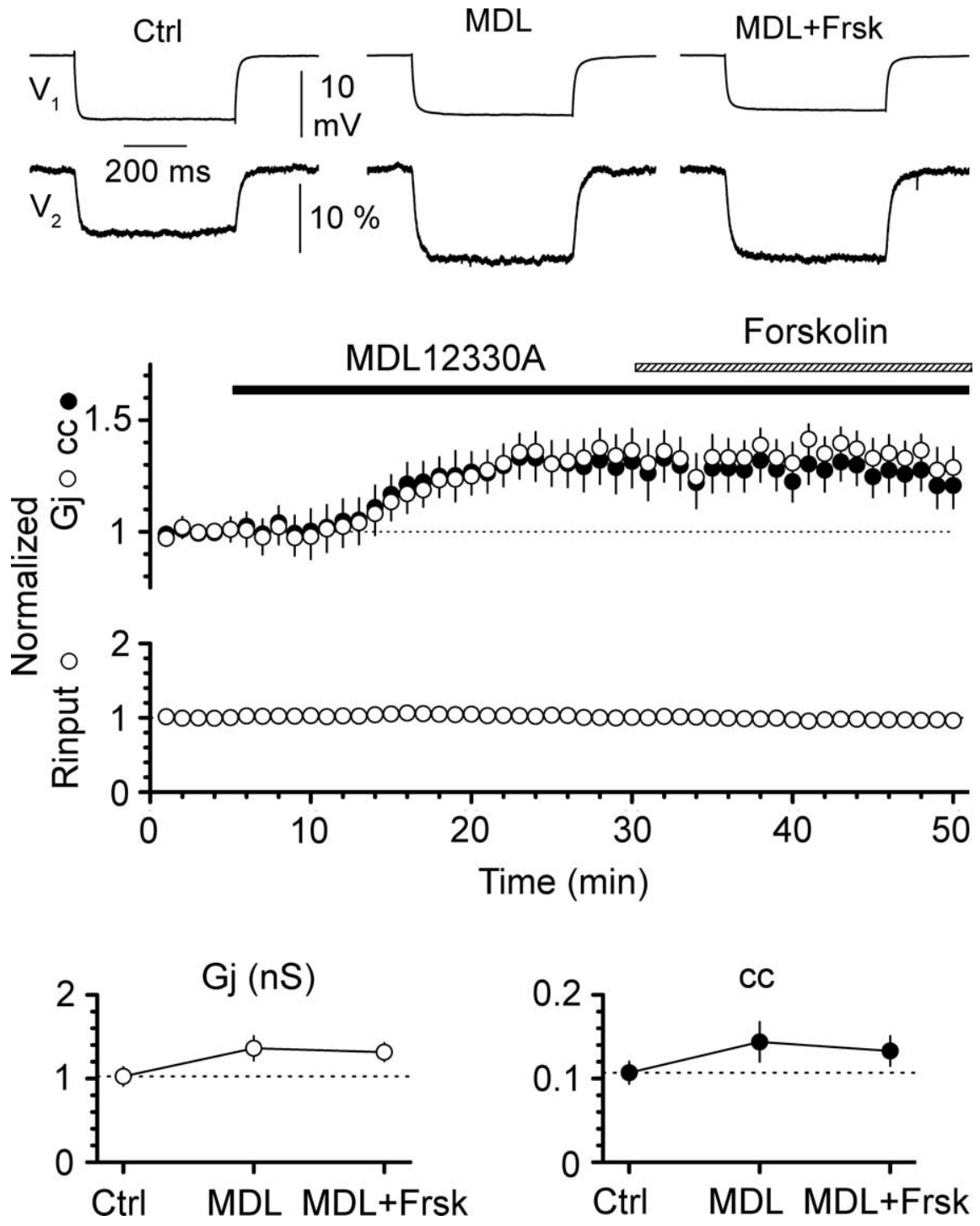

Figure 4. Pharmacological depression of basal levels of cAMP enhances coupling. Exposure of slices to the adenylyl cyclase antagonist MDL12330A (10 $\mu \mathrm{m}$ ) increases the estimated $G_{\mathrm{j}}$ and the $c c$, and prevents forskolin-induced modulation (50 $\mu \mathrm{m}$ ). Plots in the middle panel are summary graphs of normalized $G_{\mathrm{j}}$, normalized $c$ ( $n=8$ bidirectional connections), and normalized $R_{\text {input }}$ ( $n=8$ cells; values were $122 \pm 15 \mathrm{M} \Omega$ in control, $126 \pm 19 \mathrm{M} \Omega$ in MDL12330A, and $121 \pm 18 \mathrm{M} \Omega$ in MDL12330A plus forskolin). Plots of the actual values in the different conditions are shown in the bottom panel (Ctrl, control; MDL, MDL12330A; MDL + Frsk, MDL12330A plus forskolin; $n=8$ bidirectional connections). Error bars are SEM. The top insets show averaged traces from a recorded pair in the three different conditions. $V_{1}$ indicates the voltage responses from the current-injected cell (in millivolts), whereas $V_{2}$ indicates the propagated responses expressed as percentage of the steady state of $V_{1}$. Responses from the current-injected neuron were normalized to unity to express propagated responses as a percentage of $V_{1}$.

and intracellular loading of KT56720; $n=$ 16 bidirectional connections from eight pairs; $p>0.05$; W test) or estimated junctional conductance $\left(G_{j}\right.$ was $0.311 \pm 0.035$ $\mathrm{nS}$ in control compared with $0.368 \pm$ $0.057 \mathrm{nS}$ after bath addition of forskolin and intracellular loading of KT56720; $n=$ 16 bidirectional connections from eight pairs; $p>0.05$; $\mathrm{W}$ test). However, the observed result could be attributable either to intracellular loading of KT57290 or to a perturbation attributable to the repatching itself. We ruled out this latter possibility by repeating the same experiment with the difference that a control electrode (lacking KT5720) was used for repatching. In this case, forskolin was able to modulate electrical coupling similarly to what observed in the experiment shown in Figure 3 . The coupling coefficient decreased from $0.056 \pm 0.006$ in control versus $0.037 \pm$ 0.005 after bath addition of forskolin and repatching with a control electrode $(n=$ 18 bidirectional connections from nine pairs; $p<0.05$; W test). Similarly, the estimated junctional conductance was reduced from $0.522 \pm 0.063$ to $0.326 \pm$ $0.040 \mathrm{nS}$ after repatching with the control electrode ( $n=18$ bidirectional connections from nine pairs; $p<0.05$; $\mathrm{W}$ test).

\section{$\boldsymbol{\beta}$-Adrenergic modulation of coupling in stratum lacunosum-moleculare interneurons requires a cAMP/PKA pathway}

Our experiments suggested that NAmediated modulation of electrical coupling was acting via $\beta$-ARs, which, in turn, activated a cAMP/PKA pathway. We decided to test this latter point directly by recording the effect of isoproterenol under experimental conditions associated with the pharmacological blockade of the adenylyl cyclase and of PKA, respectively (Fig. 7).

Similar to the results shown in Figure 4, application of MDL12330A potentiated coupling (cc was $0.66 \pm 0.021$ in control vs

$0.141 \mathrm{nS}$ vs $0.860 \pm 0.179 \mathrm{nS}$, respectively; $n=8$ bidirectional connections from four pairs; $p>0.05$; $\mathrm{W}$ test).

To test the effect of KT5720, a different type of experiment was designed, so that exposure to the drug was restricted, as much as possible, to the pair under study. We reproduced forskolininduced depression of coupling, as shown in Figure 3. However, after $15 \mathrm{~min}$ in the experimental protocol, we gently pulled away the electrode from one of the cells of the pair, and then repatched it with an electrode filled with a solution including the PKA inhibitor $(1 \mu \mathrm{M})$. As shown in Figure 6, repatching one of the cells of the pair was sufficient to completely abolish the effect of forskolin, indicating that forskolin-induced increased levels of cAMP require PKA activity to depress coupling. Indeed, no changes were detected either in the coupling coefficient (cc was $0.038 \pm$ 0.004 in control vs $0.040 \pm 0.005$ after bath addition of forskolin
$0.082 \pm 0.023$ in the presence of MDL12330A; $n=10$ bidirectional connections from five pairs; $p<0.05 ; \mathrm{F} / \mathrm{D}$ test; whereas $G_{\mathrm{j}}$ was $0.300 \pm 0.109 \mathrm{nS}$ in the absence vs $0.397 \pm 0.136 \mathrm{nS}$ in the presence of the drug; $n=10$ bidirectional connections from five pairs; $p<0.05 ; \mathrm{F} / \mathrm{D}$ test). Under these experimental conditions, the addition of isoproterenol to the MDL12330A-containing medium had no significant effect on either coupling coefficient or estimated junctional conductance (cc was $0.082 \pm 0.023$ in MDL12330A vs $0.076 \pm 0.021$ in the presence of MDL12330A and isoproterenol; $n=10$ bidirectional connections from five pairs; $p>0.05 ; F / D$ test; whereas $G_{j}$ was $0.397 \pm 0.136 \mathrm{nS}$ in the absence vs $0.399 \pm 0.140 \mathrm{nS}$ in the presence of the isoproterenol; $n=10$ bidirectional connections from five pairs; $p>0.05 ; \mathrm{F} / \mathrm{D}$ test). We next tested whether intracellular blockade of PKA via KT5720-loaded electrodes could prevent isoproterenol-induced 
A
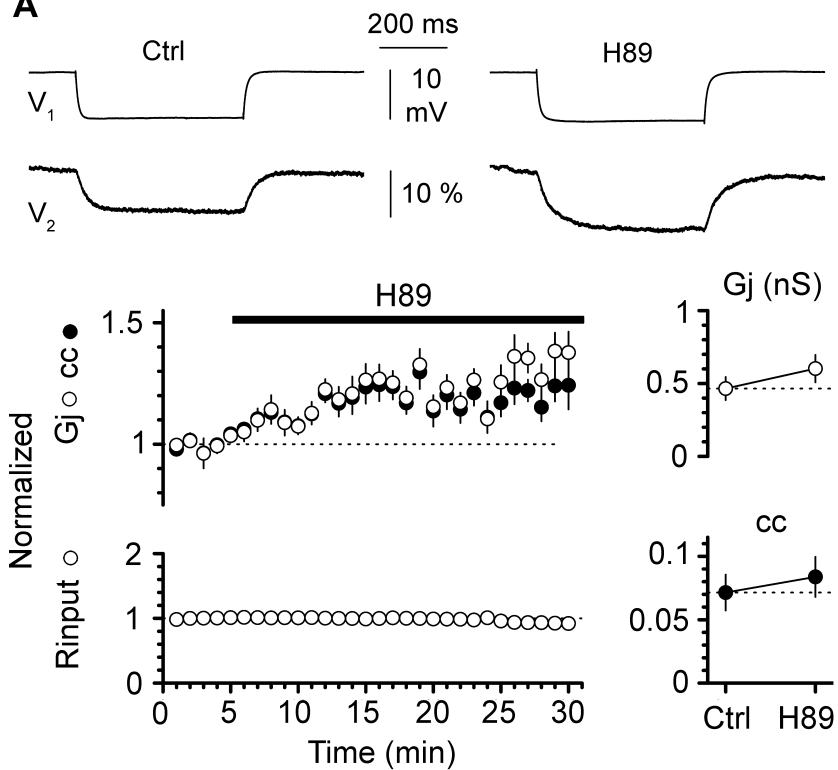
Gj (nS)

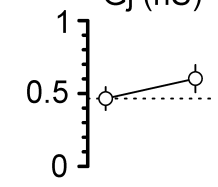

B
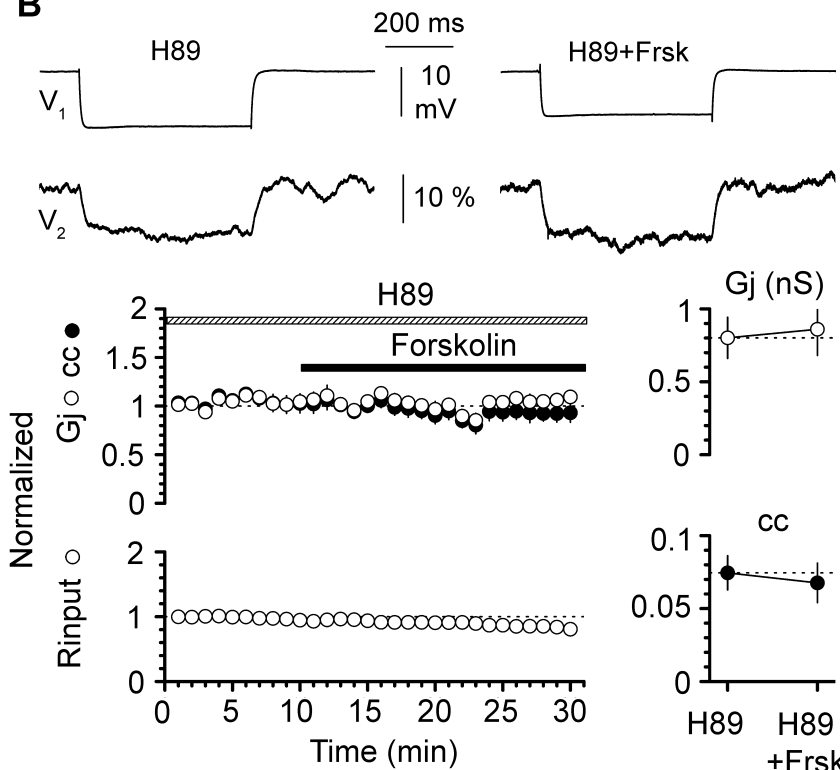

$\mathrm{Gj}(\mathrm{nS})$
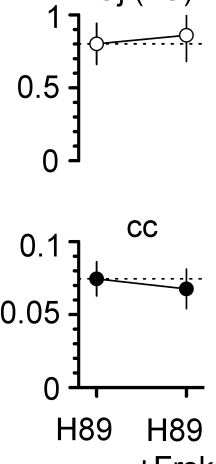

Figure 5. Blockade of PKA activity with external application of H89 $(8-20 \mu \mathrm{M})$ enhances coupling and prevents forskolin-induced modulation. $A$, Exposure of slices to the PKA antagonist H89 increases the estimated $G_{\mathrm{j}}$ and the $c c\left(n=14\right.$ bidirectional connections). Summary graphs of normalized $G_{j}$, normalized cc $\left(n=14\right.$ connections), and normalized $R_{\text {input }}(n=14$ neurons; actual values were $168 \pm 21 \mathrm{M} \Omega$ in control and $153 \pm 19 \mathrm{M} \Omega$ ) are shown on the left, whereas actual values are illustrated in the right summary graphs (Ctrl, control). Error bars are SEM. The top insets show averaged traces from a recorded pair in control and after exposure to $\mathrm{H} 89\left(V_{1}\right.$, current-injected neuron expressed in millivolts; $V_{2}$, noninjected neuron, expressed as percentage of steady-state response in $\left.V_{1}\right)$. $\boldsymbol{B}$, Same organization of the figure as in $\boldsymbol{A}$. All coupling data are averages from $n=8$ bidirectional connections. $R_{\text {input }}$ was $102 \pm 8 \mathrm{M} \Omega$ in $H 89$ versus $86 \pm 9 \mathrm{M} \Omega$ in H89 plus forskolin ( $n=8$ neurons). Notice that, in the constant presence of H89, forskolin-induced modulation $(50 \mu \mathrm{m})$ is prevented (H89, H89; H89+Frsk, H89 plus forskolin).

A
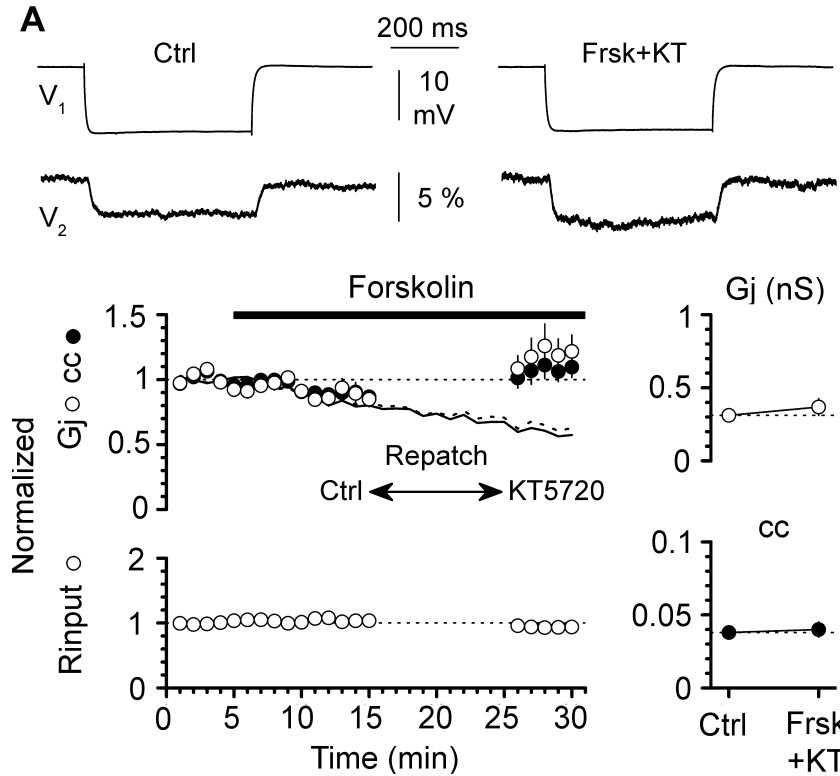
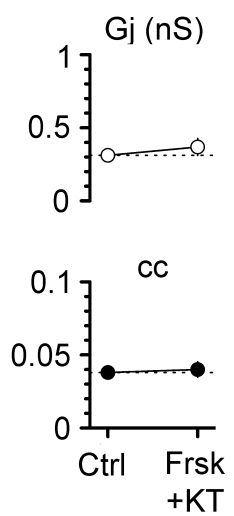

B

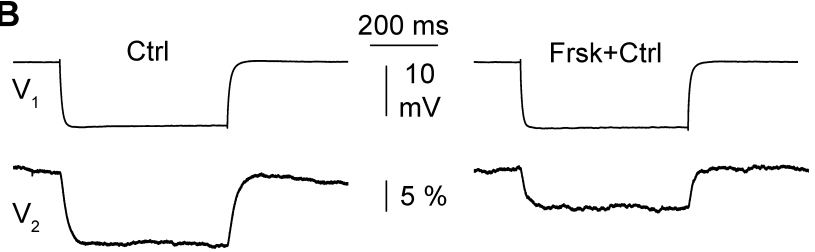

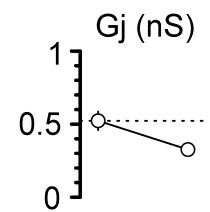
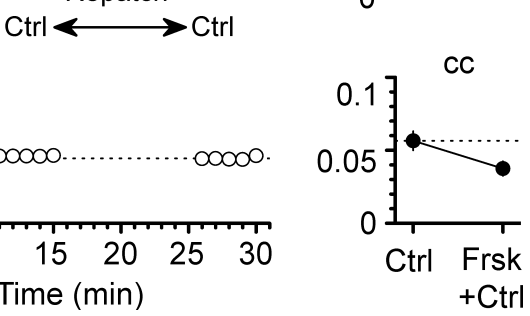

Figure 6. Intracellular blockade of PKA activity with KT5720-loaded electrodes (1 $\mu \mathrm{M})$ prevents forskolin-induced (50 $\mu \mathrm{M})$ modulation of coupling. $A$, After 10 min of forskolin application in a connected pair of neurons recorded with standard electrodes, repatching one cell of the pair with a KT5720-loaded pipette blocks forskolin-induced modulation of coupling. Summary graphs of normalized $G_{\text {j, }}$ normalized cc, and normalized $R_{\text {input }}(132 \pm 9 \mathrm{M} \Omega$ in control vs $123 \pm 9 \mathrm{M} \Omega$ after repatching with KT5720-loaded electrodes) are shown in the left for $n=16$ bidirectional connections and $n=16$ neurons, whereas actual values are illustrated in the right summary graphs (Ctrl, control; Frsk +KT, forskolin plus intracellular KT5720). Error bars are SEM. The dotted and solid lines represent the experimental results of Figure 3 for reference (dotted line, normalized $G_{j}$; solid line, normalized cc). The top insets show averaged traces from a recorded pair in control and after one cell of the pair was repatched with pipettes containing the PKA inhibitor ( $V_{1}$, current-injected neuron; $V_{2}$, noninjected neuron). $\boldsymbol{B}$, Same organization of the figure as in $\boldsymbol{A}$. However, repatching was performed with a control pipette lacking the PKA inhibitor. Notice that repatching in the absence of KT5720 does not impair forskolin-induced modulation (Frsk + KT, forskolin plus KT5720). Shown are summary data from $n=18$ bidirectional connections and $n=18$ cells. $R_{\text {input }}$ was $123 \pm 8 \mathrm{M} \Omega$ in control versus $122 \pm 6 \mathrm{M} \Omega$ after repatching with control electrodes $(n=$ 18 neurons).

modulation. As predicted, isoproterenol was ineffective when electrodes loaded with KT5720 were used (cc was $0.065 \pm 0.015$ in control vs $0.046 \pm 0.009$ in the presence of isoproterenol; $n=$ 12 bidirectional connections from six pairs; $p>0.05$; F/D test; and $G_{j}$ was $0.351 \pm 0.072 \mathrm{nS}$ in the absence vs $0.395 \pm 0.080 \mathrm{nS}$ in the presence of the drug; $n=12$ bidirectional connections from six pairs; $p>0.05$; F/D test). In conclusion, direct electrophysiological evidence from paired recordings in stratum lacunosum- 
A
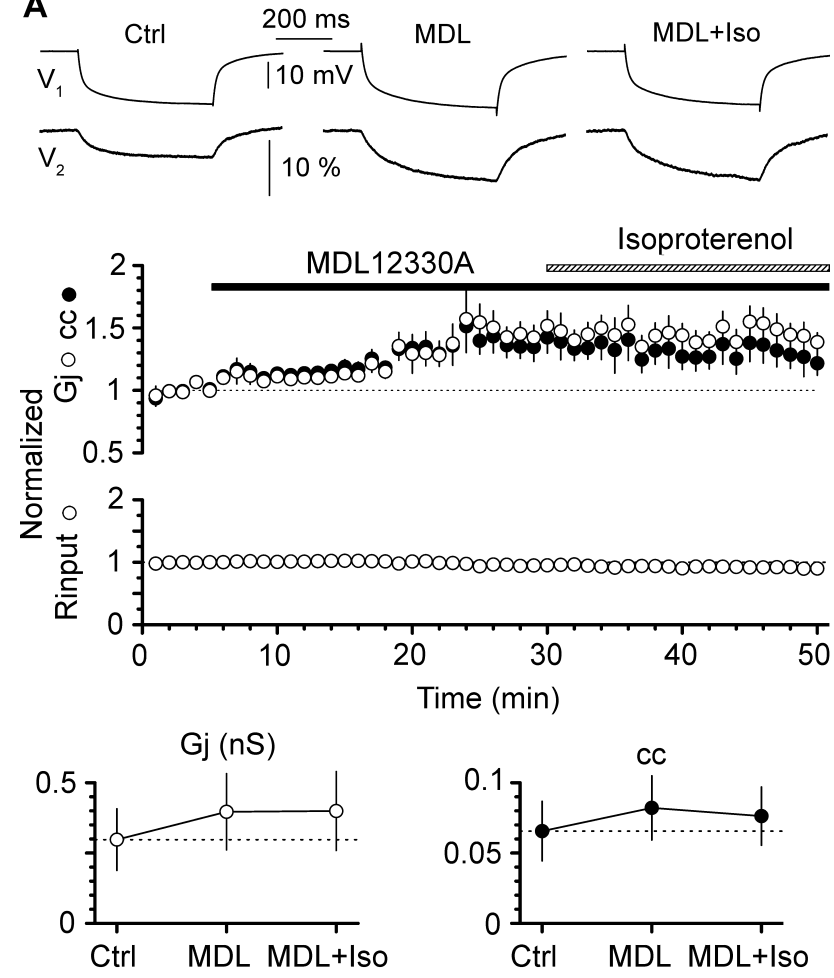

B
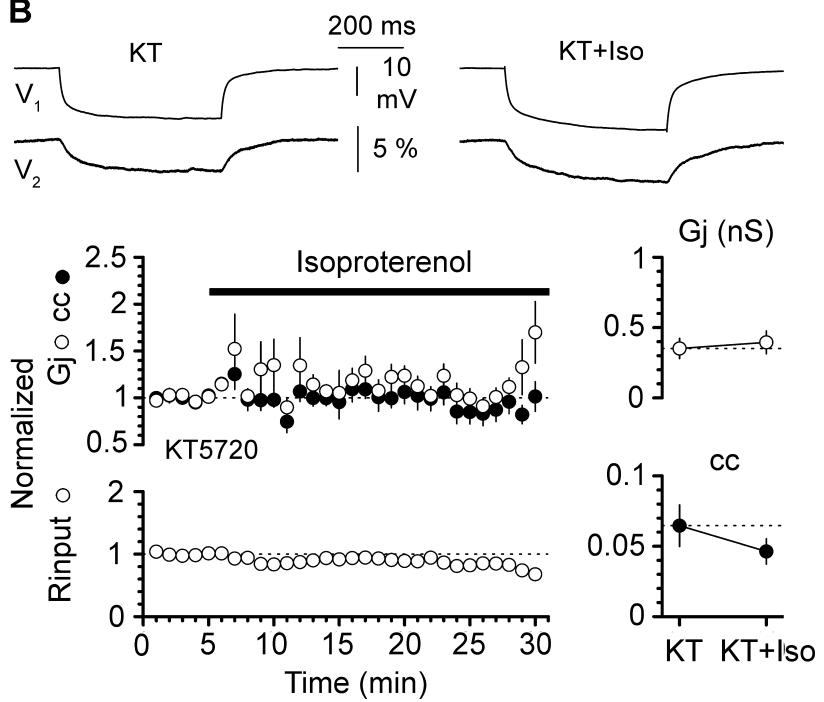

Figure 7. Isoproterenol-induced modulation of coupling depends on the activity of adenylyl cyclase and PKA. A, Application of isoproterenol (10 $\mu \mathrm{M})$ after exposure to MDL12330A $(10 \mu \mathrm{M})$ fails to depress coupling. Summary graphs of normalized $G_{\mathrm{G}}$, normalized cc $(n=10$ bidirectional connections), and normalized $R_{\text {input }}(n=10$ cells; actual values were $274 \pm 17 \mathrm{M} \Omega$ in control, $265 \pm 22 \mathrm{M} \Omega$ in MDL12330A, and $245 \pm 23 \mathrm{M} \Omega$ in MDL12330A and isoproterenol) are shown in the middle, whereas actual values are illustrated at the bottom (Ctrl, control; MDL, MDL12330A; MDL+IS0, MDL12330A plus isoproterenol). Error bars are SEM. The top insets show averaged traces from a recorded pair in the three different conditions. $V_{1}$ indicates the voltage responses from the current-injected cell, whereas $V_{2}$ indicates the propagated responses. Responses from the current-injected neuron are shown in millivolts, whereas propagated responses are expressed as percentage of the steady-state value of $V_{1} \cdot \boldsymbol{B}$, Isoproterenolinduced modulation of coupling is prevented by the inclusion of KT5720 in the recording pipettes. Notice that no effects are present either on $G_{j}$ or cc. The time course of the normalized $G_{\mathrm{j}}, c\left(n=12\right.$ bidirectional connections), and $R_{\text {input }}(n=12$ neurons) are shown at the left, whereas the actual values are shown in the right summary plots. Error bars are SEM. $R_{\text {input }}$ was $204 \pm 18 \mathrm{M} \Omega$ in control versus $156 \pm 19 \mathrm{M} \Omega$ after the addition of isoproterenol $(n=12$ cells). The top insets show averaged traces from the injected cell $\left(V_{1}\right)$ and noninjected cell $\left(V_{2}\right)$ of the pair before and after application of isoproterenol. moleculare interneurons indicates that noradrenergic activation of $\beta$-ARs modulates electrical coupling via a cAMP/PKAmediated pathway.

\section{Modulation of coupling does not depend on changes in membrane voltage-dependent conductances}

In principle, modulation of coupling attributable to modulation of voltage-dependent conductances should not be excluded a priori. Indeed, it is important to consider that variations of the coupling coefficient may be driven exclusively by changes of voltage-dependent conductances in the noninjected neuron. In addition, although the estimated junctional conductance should correct for such possibility, its calculation assumes an electrical connection between isopotential neurons, which may not always be the case.

Although the identical degree of modulation observed with Cs-QX-314- and K-methylsulfate-based intracellular solutions (supplemental Fig. 1, available at www.jneurosci.org as supplemental material) (see Materials and Methods) makes this possibility unlikely, we decided to use an additional approach to rule out the contribution of changes in voltage-dependent conductances to the observed modulation of coupling. If modulation of a voltage-dependent conductance via a $\beta$-AR/cAMP/PKA cascade was involved, then changes in membrane input resistance should be observed during pharmacological stimulation/depression of this pathway. Furthermore, changes in $R_{\text {input }}$ should be correlated to changes in coupling coefficient. Lastly, if the assumptions underlying the estimation of the junctional conductance did not hold true, then correlation with $G_{\mathrm{j}}$ should also be observed.

Figure 8 plots the variations of membrane input resistance $\left(\Delta R_{\text {input }}\right)$ observed in our pharmacological experiments dealing with the with $\beta$-AR/cAMP/PKA pathway against the variations of coupling indexes $\left(\Delta c c\right.$ and $\left.\Delta G_{\mathrm{j}}\right)$. No correlation was present in either case $\left(\Delta \mathrm{cc}: r=-0.11, n=7, p>0.05 ; \Delta G_{j}: r=-0.17, n=\right.$ $7, p>0.05)$. Thus, this analysis directly rules out any significant role of intrinsic properties, and we conclude that, under our experimental conditions, the junctional conductance is the site of the modulation.

\section{Differential effect of $\boldsymbol{\beta}$-adrenergic modulation on direct versus gap junction-propagated $\mathrm{GABA}_{\mathrm{A}}$ receptor-mediated postsynaptic currents}

What are the network effects of $\beta$-adrenergic modulation of electrical coupling? We decided to address this question by testing the hypothesis that isoproterenol-mediated reduction of coupling might affect the gap junction-dependent propagation of $\mathrm{GABA}_{\mathrm{A}}$ receptor-mediated postsynaptic currents. We recently published an experimental protocol that can differentiate between direct versus propagated input by recording from single interneurons with chloride-loaded electrodes (Zsiros et al., 2007) (for details, see Materials and Methods). In the constant presence of blockers of glutamatergic and $\mathrm{GABA}_{\mathrm{B}}$ receptor-mediated synaptic transmission, holding the membrane potential in voltage clamp at $-15 \mathrm{mV}$ revealed spontaneous currents of opposite polarities (Fig. 9). Inward currents are generated by the direct, monosynaptic chemical input received by the recorded interneuron, whereas outward currents reflect gap junction-propagated input from electrically coupled neurons. Complete blockade of both inward and outward currents was obtained in five interneurons exposed to the $\mathrm{GABA}_{\mathrm{A}}$ receptor blocker gabazine $(12.5 \mu \mathrm{M})$, as previously reported (Zsiros et al., 2007).

Overall, no consistent effects of isoproterenol $(10 \mu \mathrm{M})$ were 
detected on either the amplitude or frequency of spontaneous inward currents (amplitude was $-16.5 \pm 2.8 \mathrm{pA}$ in control $\mathrm{vs}-14.5 \pm 2.4 \mathrm{pA}$ in the presence of isoproterenol; $p>0.05 ; n=8$ cells; $\mathrm{W}$ test; and frequency was $2.5 \pm 0.7 \mathrm{~Hz}$ before and $3.1 \pm 0.9 \mathrm{~Hz}$ after the addition of the drug; $p>0.05 ; n=8$ cells). This observation is identical with the weak, nonsignificant increase of the frequency of IPSCs induced by isoproterenol in pyramidal neurons reported by Bergles et al. (1996).

In contrast, although the amplitude of outward currents was not modulated by isoproterenol, a clear, consistent effect was observed on the frequency of spontaneous outward currents, which was strongly reduced. The amplitudes of outward currents were $5.0 \pm 0.4$ and $4.0 \pm 0.4 \mathrm{pA}$ before and after application of the drug, respectively ( $p>0.05 ; n=8$ cells; $\mathrm{W}$ test $)$, whereas their frequency decreased from $0.4 \pm 0.1 \mathrm{~Hz}$ in control to $0.1 \pm 0.0 \mathrm{~Hz}$ in the presence of isoproterenol $(p<0.05$; $n=8$ cells; $\mathrm{W}$ test). The most parsimonious explanation for these results is that isoproterenol-mediated reduction of the junctional conductance blocks completely the propagation of spontaneous events originating in coupled neurons. Alternatively, isoproterenolinduced depression of coupling can reduce the amplitude of propagated events to subdetection levels, and hence affect their measured frequency. In conclusion, this result suggests that $\beta$-adrenergic modulation of coupling can have extensive effects on the functional connectivity of stratum lacunosum-moleculare GABAergic networks.

\section{Discussion}

Here, we show with direct electrophysiological means, such as paired recordings, that electrical coupling of hippocampal GABAergic networks can be modulated by noradrenaline via a cAMP/PKA-mediated pathway. Also, we show that this type of modulation is functionally significant because it alters transmission in the network by reducing gap junction-mediated propagation of postsynaptic events (Zsiros et al., 2007).

The major implication of these findings is that the modulation of gap junctions of GABAergic network must be recognized as a novel point of noradrenergic regulation of hippocampal activity.

\section{Molecular mechanism underlying noradrenergic modulation of coupling}

A general principle that has been verified in the mammalian hippocampus and neocortex is that local groups of similar GABAergic interneurons can be organized in multicellular networks (Connors and Long, 2004; Hestrin and Galarreta, 2005) connected by electrical synapses, predominantly depending on the expression of Cx36 (Belluardo et al., 2000; Rash et al., 2000; Venance et al., 2000; Deans et al., 2001; Hormuzdi et al., 2001) (for review, see Sohl et al., 2005).

The electrophysiological demonstration of modulation of coupled neurons in the mammalian CNS has been scarce (Landisman and Connors, 2005) compared with a larger number of similar studies in nonmammalian systems (Piccolino et al., 1984;
McMahon et al., 1989; Pereda et al., 2004). In addition, the generalization of dye-coupling studies of cortical and subcortical mammalian networks (Hatton, 1998) to hippocampal GABAergic interneurons is highly problematic. Gap junction functional properties appear to be strongly cell type-specific. For example, even in recombinant systems expressing the same neuronal gap junction protein $\mathrm{Cx} 36$, opposite observations were reported when different cell lines were used. Teubner et al. (2000) described no Lucifer yellow permeability when HeLa cells were used, whereas successful coupling using the same dye was shown by Srinivas et al. (1999) in PC12 or N2A cells. Also, dye coupling results in mammalian cortical neurons may not always overlap with evidence obtained with direct electrophysiological recordings (Knowles et al., 1982; Gutnick et al., 1985; Connors and Long, 2004).

Recent studies have confirmed that Cx36 [and its fish ortholog Connexin 35 (Cx35)] can be phosphorylated by PKA at two highly conserved consensus sites (Urschel et al., 2006; Kothmann et al., 2007). Paradoxically, phosphorylation may mediate opposite functional effects, probably depending on the status of a putative molecular switch located in the tip of the connexin $\mathrm{C}$ terminus (Ouyang et al., 2005). For example, cAMP/PKA activation depresses dye coupling in Cx35-expressing cell lines (Ouyang et al., 2005), but potentiates transmission at the goldfish Mauthner cell electrical synapse, which is also based on Cx35 (Pereda et al., 1994, 2004).

The most conservative explanation for our observations is that noradrenaline triggers a cascade of events resulting in the direct phosphorylation of gap junction channels formed by $\mathrm{Cx} 36$ and hence affects the strength of coupling. The ultimate molecular mechanism(s) responsible for the decrease in the junctional conductance, however, remain to be determined. Indeed, phosphorylation of connexin proteins has been associated with changes in gating, conductance states, and trafficking (Lampe 
A

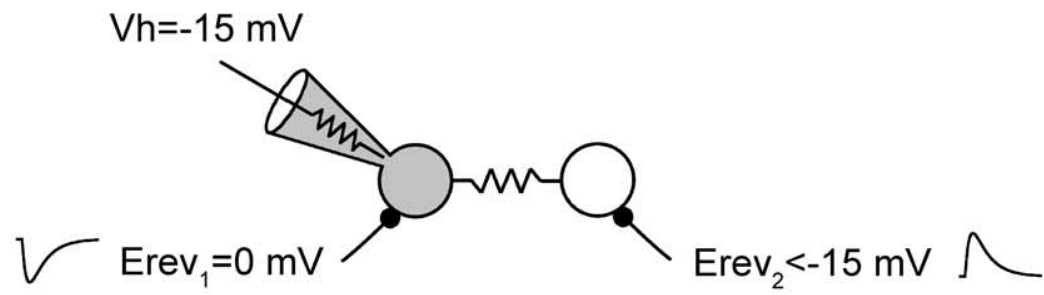

B
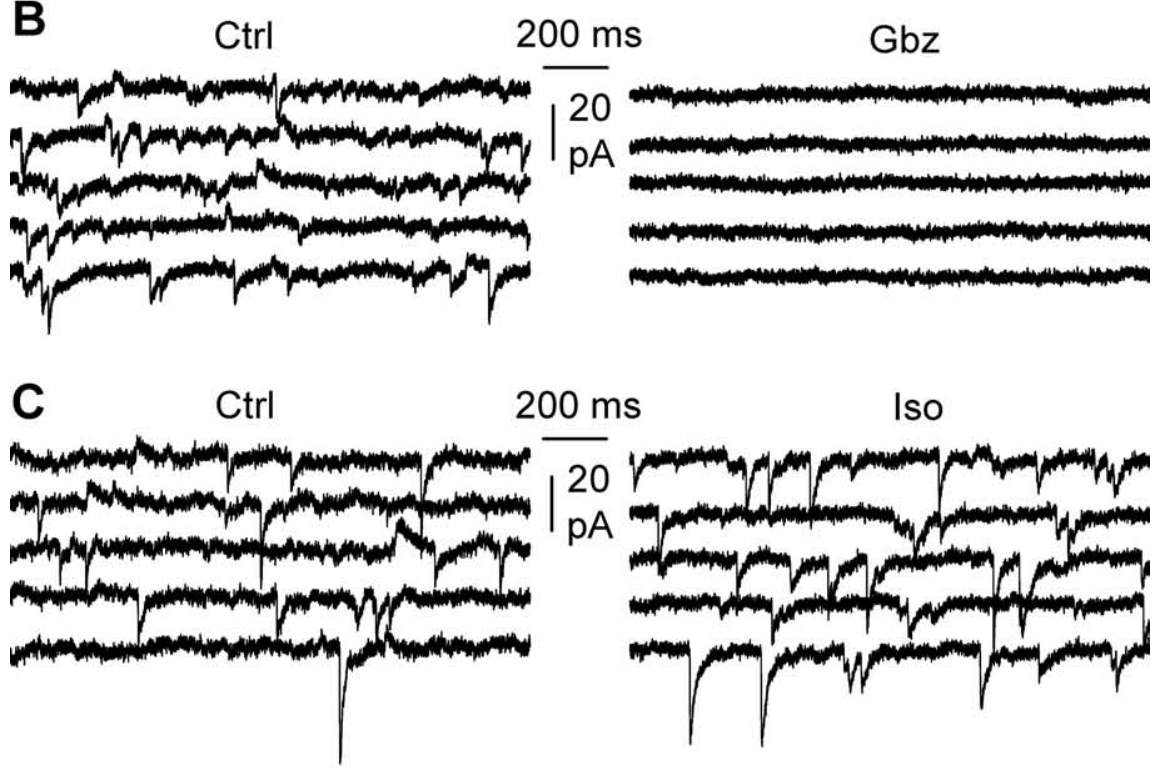

$200 \mathrm{~ms}$

Iso

D

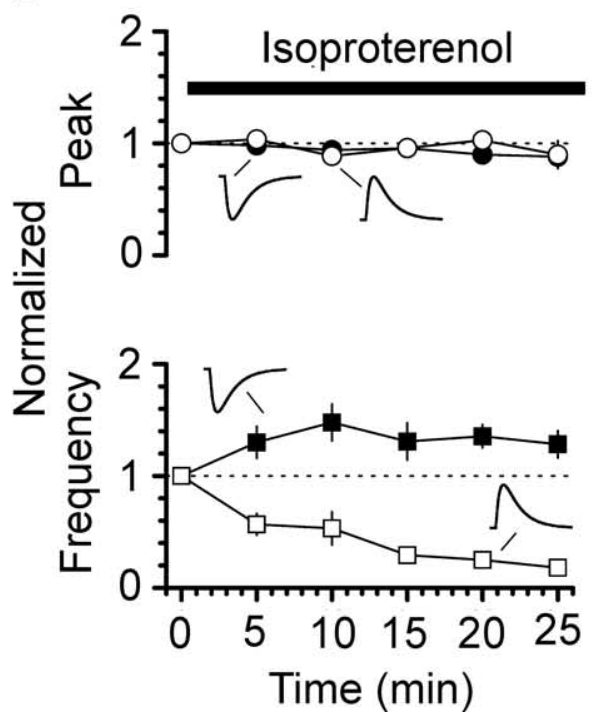

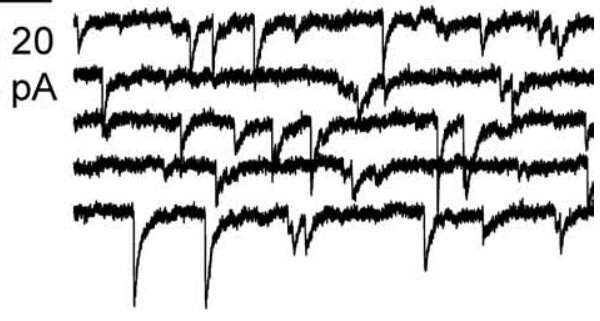

Peak (pA)
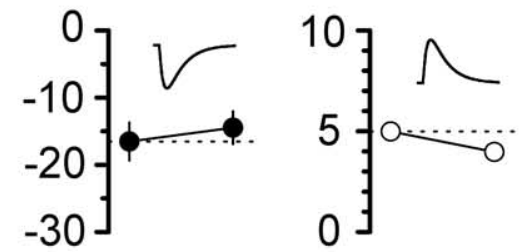

Frequency $(\mathrm{Hz})$
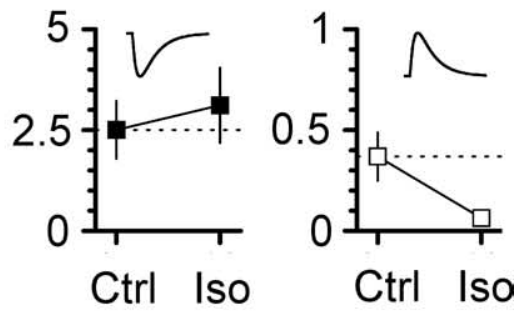

Figure 9. Isoproterenol-induced depression of coupling functionally affects propagation of $G_{A B A_{A}}$ receptor-mediated postsynaptic currents. $A$, Cartoon showing the experimental configuration. Direct $\mathrm{GABA}_{A}$ receptor-mediated input on the recorded neuron (left, gray indicates the high-chloride intracellular solution used) has an estimated reversal potential (Erev ${ }_{1}$ ) of 0 $\mathrm{mV}$. In contrast, gap junction-propagated input (right) has a lower (less than $-15 \mathrm{mV}$ ) reversal potential $\left(E^{2} \mathrm{rev}_{2}\right)\left(V_{\mathrm{h}}\right.$, holding potential). $\boldsymbol{B}$, Spontaneous synaptic events of opposite polarities recorded with chloride-loaded electrodes in the presence of blockers of glutamatergic and $G A B A_{B}$-mediated synaptic transmission: notice that both type of events are sensitive to the GABA receptor antagonist gabazine (Gbz) $(12.5 \mu \mathrm{m})$. Because of the relatively rare occurrence of outward compared with inward events, sweeps were selected from noncontiguous epochs. C, Isoproterenol (Iso) (10 $\mu \mathrm{m})$ selectively reduces the frequency of outward events. For the same reasons expressed above, noncontiguous traces are shown in the figure. $\boldsymbol{D}$, Summary graphs from $n=8$ experiments. Notice that isoproterenol does not affect the peak amplitude of either inward (white circles) or outward (black circles) currents. In contrast to inward currents (black squares), notice the selective depression of the frequency of outward events (white squares). Summary plots showing the time course of the effect of isoproterenol on normalized peak amplitude and frequency are shown at the left, whereas graphs of the absolute values are illustrated at the right (Ctrl, control; Iso, isoproterenol).

and Lau, 2004). Therefore, additional experimental work will be required to select among these various possibilities.

Modulation of homologous versus heterologous networks

Neurogliaform cells of the neocortex and hippocampus appear to be an exception to the "similar-to-similar" coupling rule (Hestrin and Galarreta, 2005). This type of cell is frequently encountered in stratum lacunosum-moleculare (Zsiros and Maccaferri, 2005), and may establish electrical connections with anatomically distinct groups of interneurons (Simon et al., 2005) as well as with other neurogliaform cells, with similar (Price et al., 2005) or distinct electrophysiological properties [Krimer et al. (2005); Zsiros and Maccaferri (2005), their Fig. 7]. Therefore, anatomical characterization alone may not be sufficient to functionally define a pair as either homologous or heterologous.

In a few experiments using K-methylsulfate-based intracellular solutions, we reproduced out previous observation of coupling between neurons with different firing patterns (Zsiros and Maccaferri, 2005). However, a systematic comparison of the modulation in homologous versus heterologous pairs was not possible in this study because of the extensive use of Cs-QX-314-based intracellular solutions in other experiments, which prevented the electrophysiological characterization of the recorded neurons.

Gap junctions of hippocampal GABAergic networks as a novel target of noradrenaline: potential antiepileptic effects

Previous work has shown that application of NA on stratum lacunosum-moleculare and other classes of interneurons causes membrane depolarization and/or tonic firing primarily via modulation of a potassium conductance (Bergles et al., 1996; Parra et al., 1998). This direct effect on interneurons was first suggested by the observation that NA increased the tonic rate of spontaneous IPSPs/IPSCs in pyramidal cells (Madison and Nicoll, 1988; Doze et al., 1991), and this was later confirmed by direct recordings of membrane potential and intrinsic currents from interneurons (Bergles et al., 1996; Parra et al., 1998). Because most of the additional effects mediated by noradrenaline on pyramidal cells favor excitability in vitro (Madison and Nicoll, 1988; Doze et al., 1991) (for review, see Nicoll et al., 1990), the increase of background IPSCs has been proposed (Bergles et al., 1996) to be the major mech- 
anism underlying the powerful locus ceruleus-mediated antiepileptic action observed in the hippocampus in vivo (Chauvel and Trottier, 1986).

Stratum lacunosum-moleculare interneurons are likely to be especially sensitive to noradrenergic modulation. Indeed, the rate of spontaneous IPSCs mediated by "slow" $\mathrm{GABA}_{\mathrm{A}}$ receptors $\left(\mathrm{GABA}_{\mathrm{A}, \text { slow }}\right)$ (Pearce, 1993), which may originate from neurogliaform interneurons (Price et al., 2005; Szabadics et al., 2007), has been reported to be selectively increased by low doses of NA (Banks et al., 2002). However, without a parallel effect on coupling, it would be difficult to explain how this powerful excitation of a GABAergic network would not translate into phasic synchronized epileptiform activity. Indeed, in the presence of low doses of the potassium blocker 4-aminopyridine, this specific GABAergic network can initiate (Sinha and Saggau, 2001) spontaneous all-or-none (Perkins, 2002) epileptiform discharges, even in the absence of ionotropic glutamatergic synaptic transmission.

Therefore, we propose that, in parallel to direct excitation mediated by $\alpha 1$-ARs, the $\beta$-AR-dependent modulation of electrical coupling is important to maintain a relatively desynchronized state of the active GABAergic network. This would prevent hypersynchronous $\mathrm{GABA}_{\mathrm{A}}$ receptor activation on postsynaptic targets (both pyramidal cells and other interneurons), which could lead to the conversion of hyperpolarizing (and hence inhibitory) $\mathrm{GABA}_{\mathrm{A}}$ receptor-mediated responses to depolarizing (and hence excitatory) events (Staley, 2004). Furthermore, the gap junction-dependent propagation of $\mathrm{GABA}_{\mathrm{A}}$ receptormediated excitatory events could contribute to the recruitment of other elements of the circuit and create a positive loop resulting in epileptiform activity (Zsiros et al., 2007). Therefore, we propose that the high density of noradrenergic innervation found in stratum lacunosum-moleculare plays an antiepileptic function by preventing the occurrence of phasic $\mathrm{GABA}_{\mathrm{A}}$ receptordependent synchronous discharges in these interneurons and thus allows a high tonic rate of desynchronized inhibitory IPSCs on pyramidal cells. The observation that gap junction blockers have a strong depressing effect on pharmacologically induced $\mathrm{GABA}_{\mathrm{A}}$ receptor-mediated epileptiform activity in these neurons (Zsiros et al., 2007) is consistent with this hypothesis.

\section{Gap junction modulation in network oscillations and higher functions}

In addition to preventing epileptiform activity, what could be the role of noradrenergic modulation of coupling in vivo? Several studies have highlighted the critical role of electrical coupling for synchronization of firing in interneurons (Connors and Long, 2004), which is believed to be important for the generation of network oscillations. In vivo recordings from various types of hippocampal GABAergic interneurons have consistently revealed a highly precise pattern of temporal activation (Somogyi and Klausberger, 2005). $\mathrm{GABA}_{\mathrm{A}}$, slow IPSCs evoked by stratum lacunosum-moleculare stimulation have been proposed to underlie theta cycle modulation of gamma rhythms (Banks et al., 2000), which may be involved in declarative memory encoding and retrieval (Osipova, 2006). Although theta activity in vivo was not directly changed in $\mathrm{Cx} 36^{-1-}$ animals, differences were indeed found in theta modulation of gamma oscillations (Buhl et al., 2003), consistent with the possibility that electrical coupling in stratum lacunosum-moleculare interneurons may directly affect the kinetics of $\mathrm{GABA}_{\mathrm{A} \text {, slow }}$ IPSCs, and thus regulate network oscillatory functions. Lastly, electrical stimulation of the locus ceruleus in vivo alters forebrain electroencephalographic activity and promotes theta activity in the hippocampus via specific acti- vation of $\beta$-AR (Berridge and Foote, 1991), which, here we have shown, are directly involved in the depression of coupling. Theta oscillations are usually associated with learning, and $\beta$-AR activation heightens synaptic plasticity (LeBeau et al., 2005). Therefore, we propose that $\beta$-adrenergic modulation of electrical coupling in GABAergic networks is likely to be involved in several neuromodulatory functions associated with hippocampaldependent higher functions.

\section{Conclusions}

We provided the first direct electrophysiological evidence of modulation of electrical coupling in cortical GABAergic networks, which is likely to underlie important physiological functions in vivo. In addition, our results open the intriguing hypothesis that modulation of electrical synapses may be, at least partly, involved in the therapeutic effects associated with pharmacological enhancement of noradrenergic neurotransmission widely used in the treatment of depression and/or other psychiatric disorders. Future work in vivo is essential to test these new ideas.

\section{References}

Agnati LF, Zoli M, Stromberg I, Fuxe K (1995) Intracellular communication in the brain: wiring versus volume transmission. Neuroscience 69:711-726.

Banks MI, White JA, Pearce RA (2000) Interactions between distinct $\mathrm{GABA}_{\mathrm{A}}$ circuits in hippocampus. Neuron 25:449-457.

Banks MI, Hardie JB, Pearce RA (2002) Development of $\mathrm{GABA}_{\mathrm{A}}$ receptormediated inhibitory postsynaptic currents in hippocampus. J Neurophysiol 88:3097-3107.

Belluardo N, Mudò G, Trovato-Salinaro A, Le Gurun S, Charollais A, SerreBeinier V, Amato G, Haefliger J-A, Meda P, Condorelli DF (2000) Expression of connexin 36 in the adult and developing brain. Brain Res 865:121-138.

Bergles DE, Doze VA, Madison DV, Smith SJ (1996) Excitatory actions of norepinephrine on multiple classes of hippocampal CA1 interneurons. J Neurosci 16:572-585.

Berridge CW, Foote SL (1991) Effects of locus coeruleus activation on electroencephalographic activity in neocortex and hippocampus. J Neurosci 11:3135-3145.

Buhl DL, Harris KD, Hormuzdi SG, Monyer H, Buzsaki G (2003) Selective impairment of hippocampal gamma oscillations in connexin-36 knockout mouse in vivo. J Neurosci 23:1013-1018.

Chauvel P, Trottier S (1986) Role of noradrenergic ascending system in extinction of epileptic phenomena. Adv Neurol 44:475-487.

Connors BW, Long MA (2004) Electrical synapses in the mammalian brain. Annu Rev Neurosci 27:393-418.

Dallal GE, Wilkinson L (1986) An analytic approximation to the distribution of Lilliefors's test statistic for normality. Am Stat 40:294-296.

Deans MR, Gibson JR, Sellitto C, Connors BW, Paul DL (2001) Synchronous activity of inhibitory networks in neocortex requires electrical synapses containing connexin 36. Neuron 31:477-485.

Do MT, Bean BP (2003) Subthreshold sodium currents and pacemaking of subthalamic neurons: modulation by slow inactivation. Neuron 39:109-120.

Doze VA, Cohen GA, Madison DV (1991) Synaptic localization of adrenergic disinhibition in the rat hippocampus. Neuron 6:889-900.

Gibbs ME, Summers RJ (2002) Role of adrenergic subtypes in memory consolidation. Prog Neurobiol 67:345-392.

Gutnick MJ, Lobel-Yaakov R, Rimon G (1985) Incidence of neuronal dyecoupling in neocortical slices depends on the plane of section. Neuroscience 15:659-666.

Hatton GI (1998) Synaptic modulation of neuronal coupling. Cell Biol Int 22:765-780.

Hestrin S, Galarreta M (2005) Electrical synapses define networks of neocortical GABAergic neurons. Trends Neurosci 28:304-309.

Hormuzdi SG, Pais I, LeBeau F, Towers SK, Rozov A, Buhl EH, Whittington MA, Monyer H (2001) Impaired electrical signaling disrupts frequency oscillations in connexin 36-deficient mice. Neuron 31:487-495.

Knowles WD, Funch PG, Schwartzkroin PA (1982) Electrotonic and dye 
coupling in hippocampal CA1 pyramidal cells in vitro. Neuroscience 7:1713-1722.

Kothmann WW, Xiaofan L, Burr GS, O'Brien JH (2007) Connexin 35/36 is phosphorylated at regulatory sites in the retina. Vis Neurosci 24:363-375.

Krimer LS, Zaitsev AV, Czanner G, Kroner S, Gonzales-Burgos G, Povysheva NV, Iyengar S, Barrionuevo G, Lewis DA (2005) Cluster analysis-based physiological classification and morphological properties of inhibitory neurons in layers 2-3 of monkey dorsolateral prefrontal cortex. J Neurophysiol 94:3009-3022.

Lampe PD, Lau AF (2004) The effect of connexin phosphorylation on gap junctional communication. Int J Biochem Cell Biol 36:1171-1186.

Landisman CE, Connors BW (2005) Long-term modulation of electrical synapses in the mammalian thalamus. Science 310:1809-1813.

LeBeau FEN, El Manira A, Griller S (2005) Tuning the network: modulation of neuronal microcircuits in the spinal cord and hippocampus. Trends Neurosci 28:552-561.

Lippe C, Ardizzone C (1991) Actions of vasopressin and isoprenaline on the ionic transport across the isolated frog skin in the presence and the absence of adenylyl cyclase inhibitors MDL12330A and SQ22536. Comp Biochem Physiol 99:209-211.

Lisman JE, Otmakhova NA (2001) Storage, recall and novelty detection of sequences by the hippocampus: elaborating on the SOCRATIC model to account for normal and aberrant effect of dopamine. Hippocampus 11:551-568.

Loy R, Koziell DA, Lindsey JD, Moore RY (1980) Noradrenergic innervation of the adult ray hippocampal formation. J Comp Neurol 189:699-710.

Maccaferri G, McBain CJ (1996) The hyperpolarization-activated current (Ih) and its contribution to pacemaker activity in rat CA1 hippocampal stratum oriens-alveus interneurones. J Physiol (Lond) 497:119-130.

Madison DV, Nicoll RA (1988) Norepinephrine decreases synaptic inhibition in the rat hippocampus. Brain Res 442:131-138.

McMahon DG, Knapp AG, Dowling JE (1989) Horizontal cell gap junctions: single channel conductance and modulation by dopamine. Proc Natl Acad Sci USA 86:7639-7643.

Milner TA, Bacon CE (1989) GABAergic neurons in the rat hippocampal formation: ultrastructure and synaptic relationships with catecholaminergic terminals. J Neurosci 9:3410-3427.

Murchinson CF, Zhang XY, Zhang WP, Ouyang M, Lee A, Thomas SA (2004) A distinct role for norepinephrine in memory retrieval. Cell 117:131-143

Nicoll RA, Malenka RC, Kauer JA (1990) Functional comparison of neurotransmitter receptor subtypes in mammalian central nervous system. Physiol Rev 70:514-565.

Oleskevich S, Descarries L, Lacaille J-C (1989) Quantified distribution of the noradrenaline innervation in the hippocampus of adult rat. J Neurosci 9:3803-3815.

Osipova D (2006) Theta and gamma oscillations predict encoding and retrieval of declarative memory. J Neurosci 26:7523-7531.

Ouyang X, Winbow VM, Patel LS, Burr GS, Mitchell CK, O’Brien J (2005) Protein kinase A mediates regulation of gap junctions containing connexin35 trough a complex pathway. Brain Res Mol Brain Res 135:1-11.

Parra P, Gulyás AI, Miles R (1998) How many subtypes of inhibitory cells in the hippocampus? Neuron 20:983-993.

Pearce RA (1993) Physiological evidence for two distinct $\mathrm{GABA}_{\mathrm{A}}$ responses in rat hippocampus. Neuron 10:189-200.

Pereda A, Nairn A, Wolzson DS, Faber DS (1994) Postsynaptic modulation of synaptic efficacy at mixed synapses on the Mauthner cell. J Neurosci 14:3704-3712.

Pereda AE, Rash JE, Nagy JI, Bennett MV (2004) Dynamics of electrical transmission at club endings on the Mauthner cells. Brain Res Brain Res Rev 47:227-244.
Perkins KL (2002) GABA application to hippocampal CA3 or CA1 stratum lacunosum-moleculare excites and interneuron network. J Neurophysiol $87: 1404-1414$

Piccolino M, Neyton J, Gerschenfeld HM (1984) Decrease of gap junction permeability induced by dopamine and cyclic adenosine $3^{\prime}: 5^{\prime}$ monophosphate in horizontal cells of turtle retina. J Neurosci 4:2477-2488.

Price CJ, Cauli B, Kovacs ER, Kulik A, Lambolez B, Shigemoto R, Capogna M (2005) Neurogliaform neurons form a novel inhibitory network in the hippocampal CA1 area. J Neurosci 25:6775-6786.

Rash JE, Staines WA, Yasumura T, Patel D, Furman CS, Stelmack GL, Nagy JI (2000) Immunogold evidence that neuronal gap junctions in adult rat brain and spinal cord contain connexin-36 but not connexin-32 or connexin-43. Proc Natl Acad Sci USA 97:7573-7578.

Raymond JR (1995) Multiple mechanisms of receptor-G protein signal specificity. Am J Physiol 269:F141-F158.

Sara JS, Dyon-Laurent C, Hervé A (1995) Novelty seeking behavior in the rat is dependent upon the integrity of the noradrenergic system. Brain Res Cogn Brain Res 2:181-187.

Simon A, Szabolcs O, Molnar G, Szabadics J, Tamas G (2005) Gapjunctional coupling between neurogliaform cells and various interneuron types in the neocortex. J Neurosci 25:6278-6285.

Sinha SR, Saggau P (2001) Imaging of 4-AP-induced GABAA-dependent spontaneous synchronized activity mediated by the hippocampal interneuron network. J Neurophysiol 86:381-391.

Sohl G, Maxiner S, Willecke K (2005) Expression and functions of neuronal gap junctions. Nat Rev Neurosci 6:191-200.

Somogyi P, Klausberger T (2005) (2005) Defined types of cortical interneurone structure space and spike timing in the hippocampus. J Physiol (Lond) 562:9-26.

Staley KJ (2004) Role of the depolarizing GABA response in epilepsy. Adv Exp Med Biol 548:104-109.

Squire LR, Stark CE, Clark RE (2004) The medial temporal lobe. Annu Rev Neurosci 27:279-306.

Srinivas M, Rozental R, Kojima T, Dermietzel R, Mehler M, Condorelli DF, Kessler JA, Spray DC (1999) Functional properties of channels formed by the neuronal gap junction protein connexin36. J Neurosci 19:9848-9855.

Szabadics J, Tamás G, Soltesz I (2007) Different transmitter transients underlie presynaptic cell type specificity of GABAA,slow and GABAA,fast. Proc Natl Acad Sci USA 104:14831-14836.

Teubner B, Degen J, Sohl G, Gudenagel M, Bukauskas FF, Trexler EB, Verselis VK, De Zeeuw CI, Lee CG, Kozak CA, Petrasch-Parwez E, Dermietzel R, Willecke K (2000) Functional expression of themurine connexin 36 gene coding for a neuron-specific gap junctional protein. J Membr Biol 176:249-262.

Urschel S, Honer T, Schubert T, Alev C, Sohl G, Worsdorfer P, Asahara T, Dermietzel R, Weiler R, Willecke K (2006) Protein kinase A-mediated phosphorylation of Connexin 36 in mouse retina results in decreased gap junctional communication between AII amacrine cells. J Biol Chem 281:33163-33171.

Venance L, Rozov A, Blatow M, Burnashev N, Feldmayer D, Monyer H (2000) Connexin expression in electrically coupled postnatal rat brain neurons. Proc Natl Acad Sci USA 97:10260-10265.

Zsiros V, Maccaferri G (2005) Electrical coupling between interneurons with different excitable properties in stratum lacunosum-moleculare of the juvenile CA1 rat hippocampus. J Neurosci 25:8686-8695.

Zsiros V, Aradi I, Maccaferri G (2007) Propagation of postsynaptic currents and potentials via gap junctions in GABAergic networks of the rat hippocampus. J Physiol (Lond) 578:527-544. 